\title{
Two independent networks of interstitial cells of Cajal work cooperatively with the enteric nervous system to create colonic motor patterns
}

\author{
Jan D. Huizinga ${ }^{1 *}$, Sarah Martz', Victor Gil1,2, Xuan-Yu Wang ${ }^{1}$, Marcel Jimenez $^{2,3}$ and Sean Parsons ${ }^{1}$ \\ ' Department of Medicine, Farncombe Family Digestive Health Research Institute, McMaster University, Hamilton, ON, Canada \\ 2 Unit of Physiology, Department of Cell Biology, Physiology and Immunology, Veterinary School, Universitat Autònoma de Barcelona, Barcelona, Spain \\ 3 Instituto de Salud Carlos III, Centro de Investigación Biomédica en Red de Enfermedades Hepáticas y Digestivas, Barcelona, Spain
}

Edited by:

Yvette France Taché, University of California Los Angeles, USA

\section{Reviewed by:}

Sean Ward, University of Nevada

School of Medicine, USA

Gianrico Farrugia, Mayo Clinic College

of Medicine, USA

*Correspondence:

Jan D. Huizinga, Farncombe Family

Digestive Health Research Institute,

McMaster University, HSC-3N8C, 1280

Main Street West, Hamilton, ON,

Canada L8S 4K1.

e-mail: huizinga@mcmaster.ca
Normal motility of the colon is critical for quality of life and efforts to normalize abnormal colon function have had limited success. A better understanding of control systems of colonic motility is therefore essential. We report here a hypothesis with supporting experimental data to explain the origin of rhythmic propulsive colonic motor activity induced by general distention. The theory holds that both networks of interstitial cells of Cajal (ICC), those associated with the submuscular plexus (ICC-SMP) and those associated with the myenteric plexus (ICC-MP), orchestrate propagating contractions as pacemaker cells in concert with the enteric nervous system (ENS). ICC-SMP generate an omnipresent slow wave activity that causes propagating but non-propulsive contractions ("rhythmic propagating ripples") enhancing absorption. The ICC-MP generate stimulus-dependent cyclic depolarizations propagating anally and directing propulsive activity ("rhythmic propulsive motor complexes"). The ENS is not essential for both rhythmic motor patterns since distention and pharmacological means can produce the motor patterns after blocking neural activity, but it supplies the primary stimulus in vivo. Supporting data come from studies on segments of the rat colon, simultaneously measuring motility through spatiotemporal mapping of video recordings, intraluminal pressure, and outflow measurements.

Keywords: ICC, ENS, colonic motility, peristalsis, colon

\section{INTRODUCTION}

Our understanding of colon motility, dysmotility, and potential treatments is still in its infancy. Satisfactory assessment of dysmotility and evaluation of treatments geared toward specific motor activities is lacking in part because of a limited understanding of basic mechanisms underlying colonic motor activity. One of the major problems is our lack of understanding of the cellular basis of motor patterns so that targeted pharmacology is difficult to achieve. Two major control systems, the interstitial cells of Cajal (ICC) pacemaker system and all parts of the enteric nervous system (ENS), are critical for normal motor patterns to occur, but their structures and functions are intertwined which has made their specific roles in normal motility control and pathophysiology of dysmotility often difficult to decipher.

The major function of colon motility is to mix and delay transport of content. Mixing motor patterns are important for creating optimal exposure of content to the absorptive surface, optimizing digestion of content, and for bacterial homeostasis. Most motor patterns are involved in mixing, including peristaltic motor patterns (Box 1). Most peristaltic motor activity does not lead to evacuation of content but to mixing and over time slow transport in anal direction. In the search for contributions of ICC to the physiology of gastrointestinal motility (Box 2 ) it has become clear that ICC and the ENS almost always work together (Box 3). In pathophysiology, injury to ICC in patients with dysmotility is always associated with injury to enteric nerves (Streutker et al., 2007; Huizinga and Lammers, 2009). This makes it difficult to delineate the specific contributions of both systems to physiology and pathophysiology and it emphasizes the close connections between the two. Although abnormal motility is often attributed to neuropathy based on structural findings (Stanghellini et al., 2005), direct associations between manometry abnormalities and abnormal neuronal functional markers are usually not available. Although abnormality of ICC in many intestinal disorders is firmly established (He et al., 2000; Wang et al., 2007; Huizinga et al., 2009), the contribution of ICC to abnormal colonic motilities is still difficult to assess because of our lack of knowledge on their contribution to normal control mechanisms, particularly in vivo.

\section{MOTOR PATTERNS IN COLON: NEUROGENIC, OR MYOGENIC?}

Studies on colonic motility have focused on slow-wave-associated motor activity and low frequency propulsive motor patterns. Early studies on the dog colon highlighted circular muscle contractions governed by slow waves originating from ICC-SMP (Smith et al., 1987; Barajas-Lopez and Huizinga, 1989). Early studies on the mouse colon highlighted propulsive contractions that were deemed neurogenic (Lyster et al., 1995; Fida et al., 1997).

In the dog colon, slow wave activity (pacemaker activity) occurs at 5-6/min (Smith et al., 1987; Barajas-Lopez and Huizinga, 1989) is associated with circular muscle contractions at the same frequency, but its role in vivo and its relationship to transit of content has not been fully elucidated. In addition, oscillatory activity is seen at a much higher frequency of $\sim 15 / \mathrm{min}$. But the contraction frequency 
associated with these high frequency oscillations is $\sim 1 / \mathrm{min}$. That is because the high frequency oscillations occur in bursts, similar to the activity of the colon longitudinal muscle layer (Chow and Huizinga, 1987). When those bursts were studied in vivo, identified as "long spike bursts" they were associated with propulsion of content (Fioramonti et al., 1980). The occurrence of the long spike bursts was clearly stimulus-dependent. When dry food replaced canned food, their frequency went up markedly together with stool increase. But what is governing the burst activity and what is the role of slow-wave-associated contractions?

In the isolated mouse colon, rhythmic propulsive motor complexes were recorded called "colonic migrating motor complexes" (CMMCs; Lyster et al., 1995; Fida et al., 1997). This was a surprising name at that time because "migrating motor complexes" (MMCs; Szurszewski, 1969) were thought to be restricted to the stomach and small intestine. MMCs, the cyclic motor pattern that develops in the stomach during fasting, is regulated by the ENS (Sarna et al., 1981a); cholinergic nerves providing excitation and nitrergic nerves providing inhibition (Rodriguez-Membrilla et al., 1995). The CMMCs were considered neurogenic because hexamethonium and TTX abolished them in the mouse colon (Spencer et al., 1995; Spencer and Bywater, 2002), and hence they were thought to be the cousins of the MMCs in the small intestine. The CMMCs occurred at $\sim 0.4 / \mathrm{min}$ (Powell et al., 2003) and were proposed to be associated with a neural pacemaker (Powell et al., 2003). It was noted that TTX caused depolarization of smooth muscle, but subsequent hyperpolarization by sodium nitroprusside did not restore CMMCs (Spencer et al., 1998a), apparently strengthening the hypothesis that CMMCs are neurogenic. The hypothesis was brought forward that inhibition of the nitrergic component might be triggering the CMMCs (Spencer et al., 1998b) but that was made unlikely when the CMMCs were observed in nNOS knockout mice (Dickson et al., 2010). In these mice CMMCs actually occurred at a higher frequency. Hence nitrergic nerves play a role in regulation of the CMMC frequency but their inhibition does not trigger CMMCs. Evidently, the exact nature of the control of CMMCs does not appear to be resolved.

In the human colon, recent studies from Dinning and colleagues (2008) have consistently shown two motor patterns based on high resolution multiple port manometry. They observed high amplitude propulsive contractions at around one per hour and much more frequent rhythmic low amplitude contractions that moved orally and well as anally (Dinning et al., 2008, 2010). In humans, in obstructed defecation, high amplitude anally propulsive contractions were reduced, and low amplitude back and forth movements became dominant (Dinning et al., 2008). In severe constipation, a marked decrease in high amplitude propulsive contractions occurred in the mid colon, based on reduced propagation from the proximal colon (Dinning et al., 2010). These motor patterns are not easily connected to early studies on human colon electrical activities. The electrical rhythm that was most consistent, i.e., occurred within a narrow frequency range and was reported in most studies was the one that occurs at 3-9/min (Sullivan et al., 1977; Snape et al., 1980; Sarna et al., 1981b), associated with "short duration spike bursts"(Bueno et al., 1980b). In vitro studies suggest that this relatively strong electrical rhythm is related to pacemaker activity in the ICC-SMP (Rae et al., 1998). It is the activity that is most frequently referred to as the human colonic slow wave. In addition, a higher frequency electrical activity is observed around $\sim 20 \mathrm{cpm}$. This is sometimes referred to as myenteric oscillations, and it has been suggested that it is generated by ICC-MP (Rae et al., 1998) but it is very likely that this high frequency activity is part of the smooth muscle mechanism of generating action potentials (Chow and Huizinga, 1987) and that it is not an exclusive property of ICC-MP. A consistent feature of the high frequency activity is that it occurs in bursts at $0.2-2 / \mathrm{min}$, always accompanied by intense action potential generation (Huizinga et al., 1985), identified in vivo as a contractile electrical complex (Sarna et al., 1981b) and "long duration spike bursts" (Bueno et al., 1980b). Long duration spike bursts are associated with strong contractile activity and are lacking in constipation (Bueno et al., 1980a). Thus far there is no hypothesis at to the underlying mechanism of the generation of the burst-type activity connected to low frequency mechanical activity (Bueno et al., 1980b; Huizinga et al., 1985) but it possibly relates to activities described by Dinning and coworkers (2008).

Early studies in the rat colon also focused on low frequency $(0.9 / \mathrm{min}$ in the proximal colon, $0.5 / \mathrm{min}$ in the distal colon) rhythmic propagating spike bursts (Ferre and Ruckebusch, 1985). These were stimulus-dependent; their frequency increased with feeding and decreased with morphine (Ferre and Ruckebusch, 1985) although it persisted after spinal cord transection, and after spinal anesthesia (Du et al., 1987). The observation that these rhythmic contractions could be observed in the rat colon in the presence of TTX (Gonzalez and Sarna, 2001b; Pluja et al., 2001) caused uncertainty about the absolute neurogenic origin of this rhythmic motor pattern. Furthermore, in the mouse colon, the electrical correlate of the CMMCs was not abolished by atropine and was associated with muscle membrane conductance changes (Spencer et al., 1998b; Powell et al., 2003). In vivo the contractions are seen to be virtually abolished by atropine, although activity re-appears in about $1 \mathrm{~h}$ (Li et al., 2002). Also in the guinea pig colon, the rhythmic propulsive contractions were sensitive to TTX and hence deemed neurogenic (D'Antona et al., 2001). If these contractions are not neurogenic under all recording conditions, other potential sources of rhythmicity might be proposed and investigated. Although the role of ICC in some motor patterns of the stomach and small intestine is firmly established (Box 2), the role of ICC in control of colonic motor patterns is far from understood and in many studies discussed above, not considered. It does not help that the motor patterns present in the colon are ambiguously defined, in part because of species differences, different recording conditions (in vivo, in vitro, etc.), and different recording methods (strain gages, intraluminal pressure, barostat, etc.). The objective of the present discussion is to contribute to knowledge and design of future experiments as to how ICC and the ENS may interact to provide coordinated motor activities in the colon.

\section{OBJECTIVE AND FORMULATION OF THE HYPOTHESIS}

We build our hypothesis around two motor patterns in the rat colon that we identified in muscle strips and in the whole colon, in vitro. In muscle strips upon moderate stretch, two rhythmic motor activities appear, one of relatively high amplitude at $0.5-1.5$ cycles $/ \mathrm{min}$ associated with prolonged depolarizations and one at a higher frequency of 13-15 cycles/min and much lower amplitude associated with slow wave activity (Pluja et al., 2001). The electrical activity of the first pattern was documented in vivo as propagating bursts of intense action potentials (Ferre and Ruckebusch, 1985). A similar 
motor pattern was seen ex vivo with strain gages (Gil et al., 2010) and in vivo in response to vagal stimulation (Tong et al., 2010). In the present study, both motor activities were seen in spatiotemporal maps derived from video recordings of the movements of the whole rat colon in vitro. We identified the two motor patterns as follows: the low frequency activity as "rhythmic propulsive motor complexes" and the high frequency activity as "rhythmic propagating ripples" (see below and Box $\mathbf{1}$ ).

We propose a hypothesis for the interaction of ICC and enteric nerves and for the cellular origin of the two rhythmic motor patterns. The hypothesis is not intended to replace all other hypotheses related to colonic motility. For example, peristaltic reflexes evoked by pellets occur (Dickson et al., 2007). The hypothesis proposed here relates to spontaneous motor patterns and motor patterns evoked by general distention. We propose that there are two independent pacemakers in the rat colon, one housed in the ICC-SMP that is independent of the ENS and the other housed in the ICC-MP that is stimulus-dependent, usually dependent on neural activity in vivo. The pacemaker activity of the ICC-SMP has a relatively fast frequency and is associated with rhythmic propagating ripples and the stimulus-dependent pacemaker activity of the ICC-MP has a relatively low and quite variable frequency and is associated with rhythmic propulsive motor complexes. The two pacemakers propagate independently. Strong propulsive propagating contractile activity occurs at the frequency and propagation velocity of the ICC-MP pacemaker. This propulsive motor pattern occurs in an anal direction, is associated with a marked increase in intraluminal pressure and is associated with outflow. The force of contraction is particularly strong when the two pacemaker activities are superimposed at the level of smooth muscle. This hypothesis explains discrepancies in the literature regarding the myogenic or neurogenic nature of the rhythmic propulsive motor complexes.

\section{MATERIALS AND METHODS PREPARATION}

In all experiments the colon was taken from adult female SpragueDawley rats of either sex weighing 250-500 g. Animals were anesthetized with isoflurane and killed by cervical dislocation. The

\section{BOX 1 |Abbreviations and explanation of terms.}

\begin{tabular}{|c|c|c|}
\hline Terms & Explanation & Comments \\
\hline $\begin{array}{l}\text { Rhythmic } \\
\text { propulsive motor } \\
\text { complex }\end{array}$ & $\begin{array}{l}\text { Low frequency, anally propagating contraction in the rat colon } \\
\text { associated with large increases in intraluminal pressure }\end{array}$ & Likely identical to CMMCs (below) \\
\hline $\begin{array}{l}\text { Rhythmic } \\
\text { propagating } \\
\text { ripple }\end{array}$ & $\begin{array}{l}\text { High frequency, low amplitude contraction in the colon. } \\
\text { Propagates either orally or anally }\end{array}$ & \\
\hline ICC-MP & ICC associated with the myenteric plexus & Also called ICC-AP or ICC-MY \\
\hline ICC-SMP & ICC associated with the submuscular plexus in the colon & \\
\hline ICC-DMP & $\begin{array}{l}\text { ICC associated with the deep muscular plexus in the small } \\
\text { intestine }\end{array}$ & $\begin{array}{l}\text { The anatomical difference between ICC-SMP and ICC-DMP is that } \\
\text { only in the latter a thin layer of circular muscle separates the ICC } \\
\text { from the submucosa }\end{array}$ \\
\hline ICC-IM & Intramuscular ICC & Found within in both circular and longitudinal muscle layers \\
\hline Slow wave(s) & $\begin{array}{l}\text { Electrical activity proposed to originate from ICC-SMP in the } \\
\text { rat colon (Pluja et al., 2001) }\end{array}$ & Likely similar in other species including human \\
\hline $\begin{array}{l}\text { Rhythmic } \\
\text { transient } \\
\text { depolarizations }\end{array}$ & $\begin{array}{l}\text { Proposed here to underlie rhythmic propulsive motor } \\
\text { complexes in the colon and proposed to originate from } \\
\text { ICC-MP }\end{array}$ & Called "cyclic depolarizations" in the rat colon (Pluja et al., 2001) \\
\hline CMMC & $\begin{array}{l}\text { Colonic migrating motor complex, described in the mouse } \\
\text { colon (Fida et al., 1997) }\end{array}$ & $\begin{array}{l}\text { Likely identical to "rhythmic propulsive motor complexes" described } \\
\text { here. The term CMMC is not used here because of its resemblance } \\
\text { to small intestinal MMC's that are controlled differently }\end{array}$ \\
\hline $\begin{array}{l}\text { Giant migrating } \\
\text { contractions }\end{array}$ & $\begin{array}{l}\text { Rarely occurring propulsive contractions that precede } \\
\text { defecation (Karaus and Sarna, 1987) }\end{array}$ & $\begin{array}{l}\text { Confusing term since it is also used to describe other motor patterns } \\
\text { such as the rhythmic propulsive motor complexes in the rat colon } \\
\text { that are not associated with defecation (Gonzalez and Sarna, 2001a) }\end{array}$ \\
\hline Peristaltic reflex & $\begin{array}{l}\text { A reflex that is evoked by local distention and involves afferent } \\
\text { sensory neurons, interneurons, and motor neurons leading to a } \\
\text { contraction at the oral end and relaxation at the anal end of the } \\
\text { stimulus (Spencer and Smith, 2001) }\end{array}$ & $\begin{array}{l}\text { Often erroneously used to describe a wide variety of peristaltic } \\
\text { motor patterns. In textbooks and journal articles, "peristaltic reflex" } \\
\text { and "peristalsis" is often erroneously used interchangeably }\end{array}$ \\
\hline Peristalsis & $\begin{array}{l}\text { A circumferential circular muscle ring contraction that } \\
\text { propagates and causes movement of content in anal direction }\end{array}$ & $\begin{array}{l}\text { The "rhythmic propulsive motor complexes" described here fulfill } \\
\text { the criteria for a peristaltic motor pattern }\end{array}$ \\
\hline Retro-peristalsis & $\begin{array}{l}\text { A circumferential circular muscle ring contraction that } \\
\text { propagates and causes movement of content in oral direction }\end{array}$ & \\
\hline
\end{tabular}




\section{BOX 2 |Theories about the physiological roles of interstitial cells of Cajal.}

Ramon y Cajal (1893) theorized that the cells which later became known as ICC, were part of the sympathetic nervous system. They were the last cells of the neural network, communicating with smooth muscle cells. That conclusion was largely based on the fact that ICC were stained together with the enteric nerves when using methylene blue and other "neural" stains. For the following decades, anatomists discussed whether ICC were nerves, connective tissue cells, or fibroblasts (Thuneberg, 1999).

Early on Keith (1915) speculated that ICC might be pacemaker cells, a theory picked up by several investigators over the years including scientists from the University of Utrecht between the 1920s and 1950s (Leeuwe, 1937; Nelemans and Nauta, 1951). Preceding and initiating the recent explosion of studies on the physiological role of ICC were works from Thuneberg and colleagues (Rumessen et al., 1982; Thuneberg, 1982) and Faussone-Pellegrini et al. (1977). These scientists proposed a role for ICC as pacemakers based on their extensive ultrastructural studies of ICC and the then emerging facts and speculations on the origin of slow wave activity in smooth muscle (see the interesting discussion in Tomita, 1981). The theory of ICC as pacemaker cells became established when two studies showed a correlation between absence of pacemaker activity and absence of ICC-MP in the mouse small intestine, using c-kit mutant mice; $c$-kit is the receptor for Steel Factor, an essential growth factor for this ICC subtype (Ward et al., 1994; Huizinga et al., 1995). The theory was further supported when isolated ICC, but not isolated smooth muscle cells, were shown to have rhythmic electrical activity (Koh et al., 1998; Thomsen et al., 1998). It was understood then that this rhythmic electrical activity was the origin of the slow waves that are recorded from smooth muscles.

A role for ICC as pacemakers has found strong support in the stomach where early studies by Bauer et al. (1985) on the dog antrum set the tone. Now both ICC-MP and ICC-IM are proven to be part of the pacemaker network (Hirst and Edwards, 2006; Hirst et al., 2006). Peristaltic activity in the stomach after feeding occurs in a dramatically rhythmic fashion at the slow wave frequency in all animal species studied. The ICC networks provide pacemaker activity as well as electrical conduction pathways. Although peristalsis is always associated with anally directed transport of content, a major function of peristaltic activity is mixing and grinding when content is forced against the closed or semi-closed pyloric sphincter and swept back into the stomach.

The small intestine was the first organ to be assessed for ICC pacemaker activity in many different laboratories, starting with Thuneberg and Rumessen's work (Thuneberg, 1982). Correlations between ICC generated slow waves and peristaltic contractions were demonstrated in the mouse small intestine (Der-Silaphet et al., 1998). Work from Lammers has clarified propagation characteristics in the small intestine (Lammers and Slack, 2001). Different techniques have confirmed their role as pacemaker cells (Park et al., 2006); reviewed in (Sanders et al., 2006; Streutker et al., 2007; Huizinga et al., 2009).

The role of ICC as pacemakers in the colon is more controversial. Research started with extensive work on the dog colon where strong evidence was accumulated that ICC-SMP functioned as pacemaker cells (Chow and Huizinga, 1987; Smith et al., 1987; Liu and Huizinga, 1993). Thereafter attention shifted to the small intestine, but recently the mouse and rat colon have received substantial attention as discussed in the present communication.

ICC are intimately linked to vagal afferent innervation (Fox et al., 2000; Powley et al., 2008) which has been proposed as evidence for a role of ICC in stretch sensing. Thuneberg has provided interesting evidence for this hypothesis in the small intestine related to his observation that there are transient peg and socket junctions formed between ICC and smooth muscle cells, in particular associated with segmentation (Thuneberg and Peters, 2001). Evidence for a role of ICC as stretch sensors was also provided in the stomach (Won et al., 2005) and mechanosensitive ion channels have been identified in ICC (Park et al., 2005; Kraichely and Farrugia, 2007).

\section{BOX 3 |Theories about interactions between ICC and enteric nerves.}

As noted in Box 2, Ramon y Cajal (1893) thought ICC to be part of the sympathetic nervous system. Since then the relationship between ICC and nerves has been a topic of intense discussion (Thuneberg, 1999). A breakthrough was achieved when HeatherYoung et al. (1996) discovered that the embryological development of ICC came from mesenchymal cells and not the neural crest.

It has always been recognized that there is an intimate relationship between ICC and enteric nerve varicosities. Ultrastructural studies suggest that every ICC has a close connection to nerves, which is not the case for every smooth muscle cell. The nature of the connection is either a close contact of $20-200 \mathrm{~nm}$ or a synapse-like contact of $\sim 20 \mathrm{~nm}$ with features of synapses such as membrane thickening. Also synaptic proteins have been demonstrated in these structures (Beckett et al., 2005). This is not to say that smooth muscle cells never have synapse-like connections with enteric nerve varicosities and it is possible that their number is underestimated (Mitsui and Komuro, 2002; Huizinga et al., 2008a).

It seems logical to assume that the major function of innervation of ICC is to have neural control over pacemaker activity (Huizinga et al., 2004). This is consistent with the effects of muscarinic, purinergic, and tachykinergic neurotransmitters on pacemaking (Huizinga et al., 1984; Sanders and Smith, 1986; lino et al., 2004; Furuzono et al., 2005; So et al., 2009) and on specific ion channels in cultured ICC (McKay and Huizinga, 2006). Consistent with these physiological effects is the presence of neurotransmitter receptors on ICC. For example, in the proximal colon of the guinea pig ICC-IM and ICC-MP express $\mathrm{M} 2$ receptors (lino and Nojyo, 2006). Another example is that ICC of the human colon express NK receptors, though their distribution varies widely amongst the different ICC subtypes (Faussone-Pellegrini, 2006).

It is interesting to note that there are few studies that attempt to prove a physiological role for ICC-MP in the colon. The hypothesis presented here requires an intensive communication between excitatory neurotransmitters and colonic ICC-MP. Not many studies have addressed receptor composition in colonic ICC-MP nor assessed physiological interactions. Myenteric interstitial cells of Cajal of mouse colon do express several nitric oxide synthase isoforms (Vannucchi et al., 2002).

Evidence has been presented to suggest that ICC are an essential intermediary for muscle innervation (Nelemans and Nauta, 1951; Burns et al., 1996). It appeared that without ICC-IM the musculature was not properly innervated by nitrergic (Burns et al., 1996) and cholinergic (Ward et al., 2000) nerves explained by destruction of neurotransmitter on its way to smooth muscle cells (Ward, 2000). Evidence against this intercalation hypothesis was summarized recently (Goyal and Chaudhury, 2010). 
entire colon was removed and placed in warm oxygenated Krebs solution. Krebs solution consisted of $\left(\mathrm{mmol} \mathrm{L}^{-1}\right) \mathrm{NaCl} 118.1, \mathrm{KCl}$ 4.8, $\mathrm{NaHCO}_{3} 25, \mathrm{NaH}_{2} \mathrm{PO}_{4} 1.0, \mathrm{MgSO}_{4} 1.2$, glucose 11.1, and $\mathrm{CaCl}_{2}$ 2.5. The contents of the colon were flushed out using warmed Krebs. The colon was submerged into an organ bath containing warmed oxygenated Krebs solution $\left(37^{\circ} \mathrm{C}\right)$. The distal and proximal ends were cannulated and fixed to the bottom of the organ bath. Inflow of Krebs was kept at $6 \mathrm{~cm} \mathrm{H}_{2} \mathrm{O}$. Intraluminal pressure was measured at the mid colon using a tube from the distal end attached to the outflow tube. The tube was attached to a pressure transducer. The outflow was measure using a second pressure transducer with a tube placed into a container collecting outflow from the colon segment. The colon was left to equilibrate for $20-30 / \mathrm{min}$. A video camera was mounted above the preparation and each experiment was recorded in its entirety. For the data described below, 18 experiments on 18 animals were analyzed.

\section{EXPERIMENTAL PROTOCOL}

Krebs solution was introduced into the proximal end and motility was recorded with the video camera. Intraluminal pressure and outflow were recorded simultaneously. Hundred micromolar lidocaine was used to block neural activity and $0.2 \mu \mathrm{M}$ tetrodotoxin (TTX) was used to verify the lidocaine results. Two hundred micromolar nitro-L-arginine (L-NNA) was used to inhibit nitric oxide synthesis. All drugs were from Sigma-Aldrich (Oakville, ON, Canada).

\section{SPATIOTEMPORAL MAPPING}

A "spatiotemporal map" is an image representation of motor activity. Colon width (coded as image intensity, black to white) is calculated at each point along the colon's length (image Y-axis), for each video frame (image $\mathrm{X}$-axis). Diagonal streaks of dark color represent propagating contractions. Maps were calculated with a custom Java algorithm loosely based on (Hennig et al., 1999).

\section{IMMUNOHISTOCHEMISTRY}

Both whole-mounts and frozen sections were made from mid colon of rats and mice. Musculature and submucosal whole-mounts were prepared to reveal the networks of ICC-MP and ICC-SMP, respectively. Tissues were fixed in either $4 \%(\mathrm{w} / \mathrm{w})$ paraformaldehyde in phosphate-buffered saline (PBS) for $1 \mathrm{~h}$ for rat tissues or ice-cold acetone for $10 / \mathrm{min}$ for mouse tissue. After fixation preparations were incubated with $1 \%$ bovine serum albumin for $1 \mathrm{~h}$ to block non-specific staining. Tissues were incubated with primary antibodies overnight, followed by secondary antibody incubation of $1 \mathrm{~h}$ at room temperature. Primary antibodies were: 1:100 rabbit anti-c-Kit (Dako Canada Inc., Burlington, ON, Canada) for rat tissue, 1:200 rat anti-c-Kit (Cedarlane, Oakville, ON, Canada) for mouse tissue and 1:100 goat anti-vesicular acetylcholine transporter (VAChT; Santa Cruz Biotechnology, Santa Cruz, CA, USA) for both rat and mouse tissues. Secondary antibodies were either 1:600 Cy3, 1:100 Cy2 conjugated IgG (Jackson ImmunoResearch, West Grove, PA, USA), or 1:200 biotinylated IgG from Vectastain ABC Kit (Vector Lab. Inc., Burlingame, CA, USA). For ABC staining, 3,3'-diaminobenzidine (DAB) was used as a peroxidase substrate. All antibodies were diluted in $0.3 \%$ Triton X-100 in PBS (pH 7.4). Control tissues were prepared by omitting primary antibodies.
Tissues were examined with either a confocal laser scanning microscope (Zeiss LSM 510, Germany) with an excitation wavelength appropriate for fluorescein isothiocyanate $(494 \mathrm{~nm})$ and Texas Red $(595 \mathrm{~nm})$; or with a digital camera (Sony 3CCD, Model no. DXC930; Tokyo, Japan) attached to a conventional microscope.

\section{RESULTS}

\section{TWO MOTOR PATTERNS AND THEIR INTERACTION}

Distention of the colon to $\sim 6 \mathrm{~cm} \mathrm{H}_{2} \mathrm{O}$ intraluminal pressure in vitro, induced motor activity showing two patterns (Figures 1 and 2). The first pattern consisted of rhythmic, low frequency (0.3-2/min; average $1.2 \pm 0.2 / \mathrm{min})$, large amplitude contractions which began in the proximal colon and propagated in an anal direction (Figures 1A-C). The duration of these contractions was $34 \pm 4 \mathrm{~s}$. Frequency and propagation velocity in the
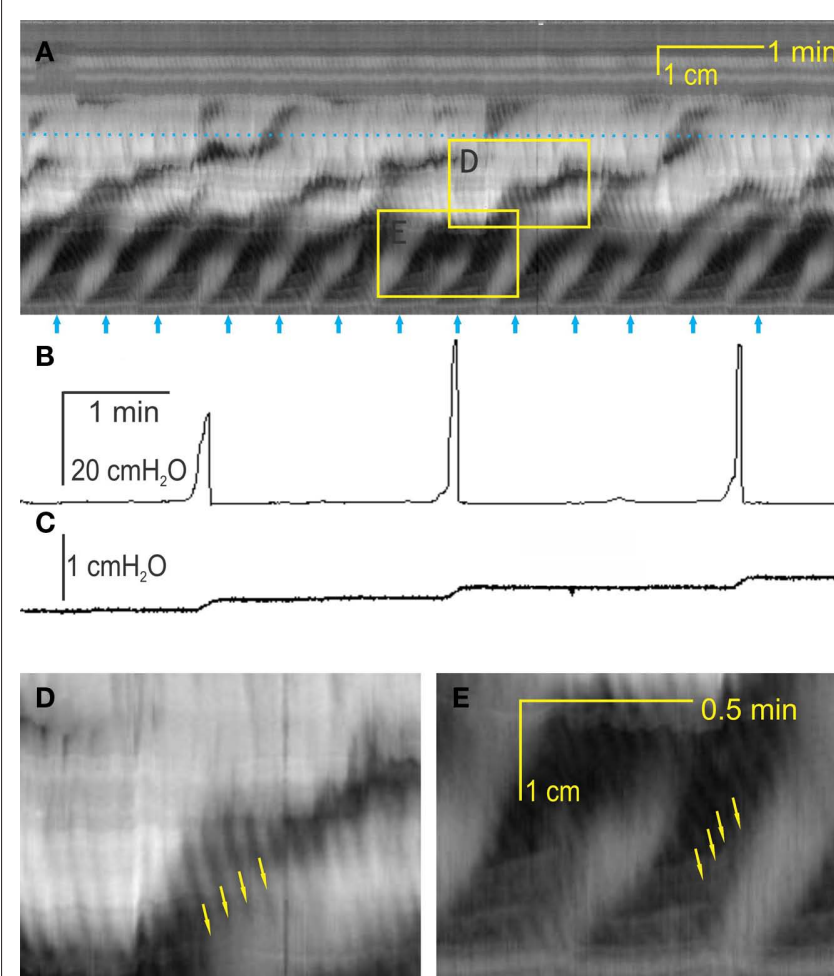

FIGURE 1 | Two motor patterns, intraluminal pressure changes, and outflow. (A) A spatiotemporal map of rat colonic motility (circular muscle activity) over a 20-min period. Black is narrowing of the lumen, hence circular muscle contraction and white is relaxation or widening of the lumen. For each map, the Y-axis is distance along the colon (proximal colon = bottom third, mid colon = middle third, distal colon = top third); the $\mathrm{X}$-axis is time. Thirteen rhythmic propulsive motor complexes are seen to propagate anally in the proximal colon [arrows underneath $(\mathbf{A})$ ] and some are continuing to propagate into the mid colon at decreased velocity. Within these motor complexes, rhythmic propagating ripples occur at a much higher frequency and propagate in a different direction [arrows in $\mathbf{( D , E )}$ ]. The dotted line in $(\mathbf{A})$ indicates the position of the intraluminal pressure transducer. The rhythmic propulsive motor complexes in the mid colon are accompanied by strong increases in intraluminal pressure (B) and outflow of content (C), measured simultaneously. The outflow (C) was collected in a cylinder and measured as increase in pressure measured at the bottom of the cylinder. (D) Enlargement of box in the mid colon. (E) Enlargement of box in the proximal colon. 
proximal colon was usually quite regular (Figure 1A, arrows). Under our experimental conditions $\left(\sim 6 \mathrm{~cm} \mathrm{H}_{2} \mathrm{O}\right.$ intraluminal pressure) these contractions, starting in the proximal colon, did not all propagate into the mid colon and usually there was a pattern to it, i.e., one out of three or four $(\sim 40 \%)$ would

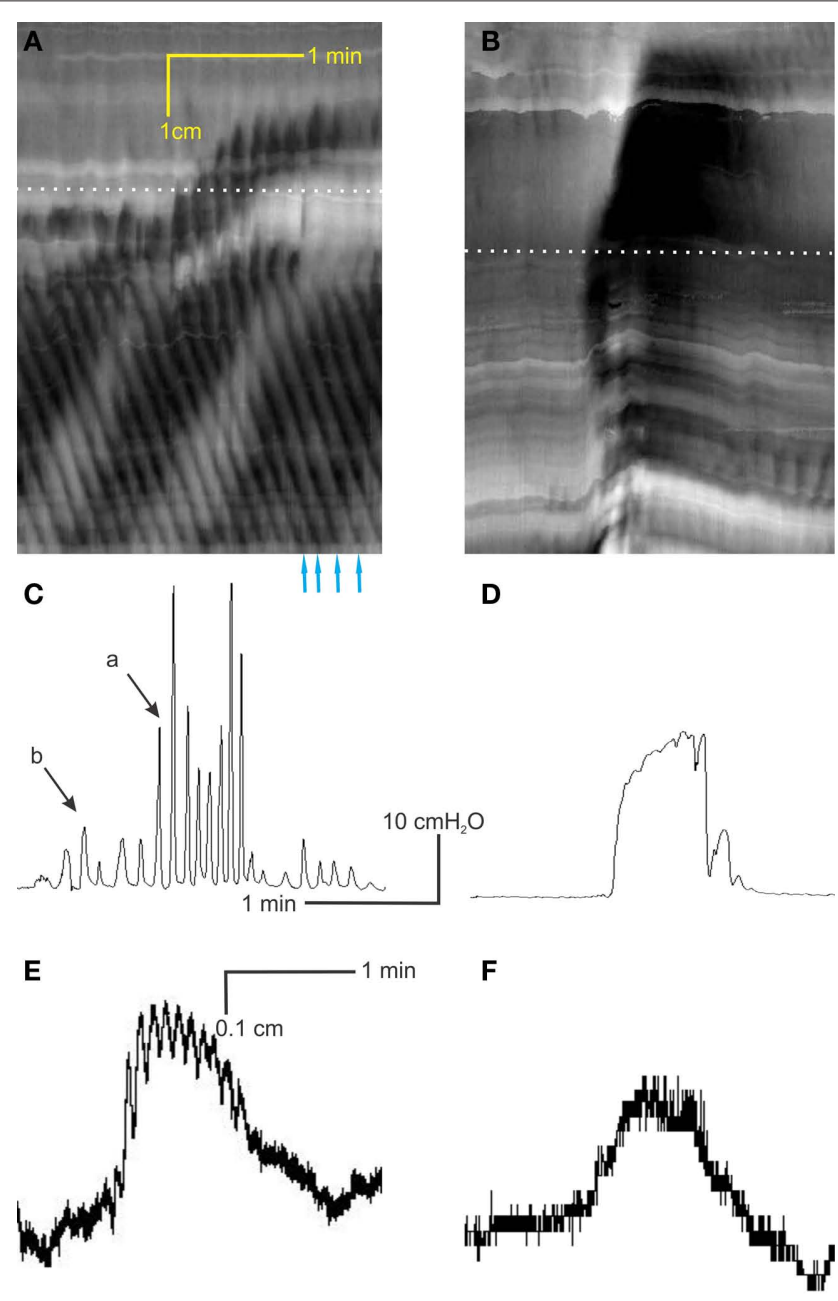

FIGURE 2 | Interaction between the two motor patterns. (A) The rhythmic propagating ripples are part of the rhythmic propulsive motor complexes. One can see a marked increase in amplitude (blackness) of the ripple contractions within the rhythmic propulsive motor complexes as compared to the time period in between these complexes. However, the propagation of the two types of activity appears independent. (B) When the rhythmic propulsive motor complexes are very strong, the rhythmic propagating ripples appear to summate and relatively long-lasting constrictions (broad black bands) occur. (C) Intraluminal pressure changes accompanying the rhythmic propulsive motor complexes in A at the dotted line. Strong intraluminal pressure changes occur during the rhythmic propulsive motor complexes but they consist of contractions at the rhythm of the rhythmic propagating ripples. (D) The rhythmic propulsive motor complexes are accompanied by strong intraluminal pressure increases. Here, the high frequency intraluminal pressure transients are seen to summate which leaves a single pressure change [occurring at the dotted line in (B)]. (E) Presented here is a single line from the data file underlying (A) (at dotted line), showing in a different way the fact that the rhythmic propagating ripples have a much higher amplitude during the time frame of the rhythmic propulsive motor complexes than outside of that time frame. (F) Single line from data file underlying (B) at dotted line. propagate into the mid colon; consequently, the average frequency in the mid colon was $0.5 \pm 0.1 / \mathrm{min}$. Upon reaching the mid colon, the velocity might become irregular and the contraction terminated usually at the beginning of the distal colon. As this motor activity was always propagating in an anal direction and was large enough in amplitude, it caused large increases in intraluminal pressure (Figure 1B) to induce outflow (Figure 1C), hence we called the contractions "rhythmic propulsive motor complexes."

The second pattern consisted of rhythmic, high frequency (6-12/min; average $9.5 \pm 0.5 / \mathrm{min}$; the duration was short $5 \pm 1 \mathrm{~s})$, small amplitude contractions which were confined to the proximal and mid colon. Propagation origin, direction, and velocity were quite variable (Figures 1, 2, and 3A). We called these contractions "rhythmic propagating ripples." The propagation direction was often opposed to that of the rhythmic propulsive motor complexes (Figures $\mathbf{1 E}$ and $2 \mathrm{~A}$ ) and the presence of one contraction did not depend on the presence of the other. Their amplitude was large enough to be registered as intraluminal pressure transients, but not large enough to cause outflow, even when propagation was anal, except when the two motor patterns coincided (Figures 1 and 2 ).

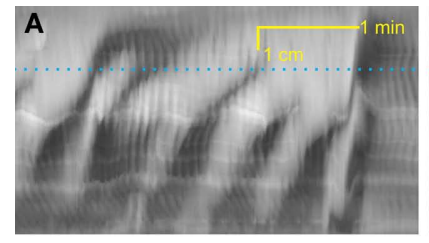

B

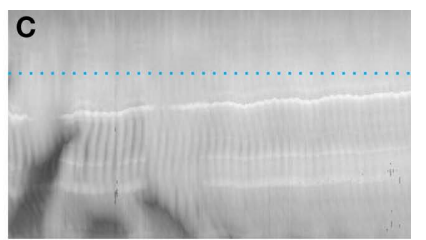

D

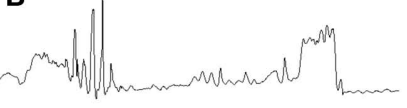

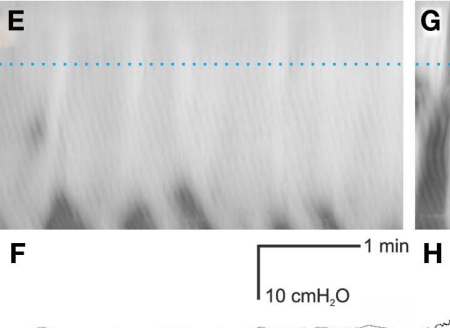

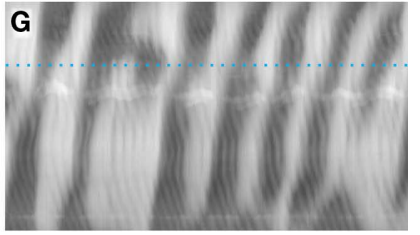

$\mathbf{F}$

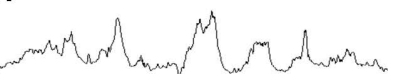

I

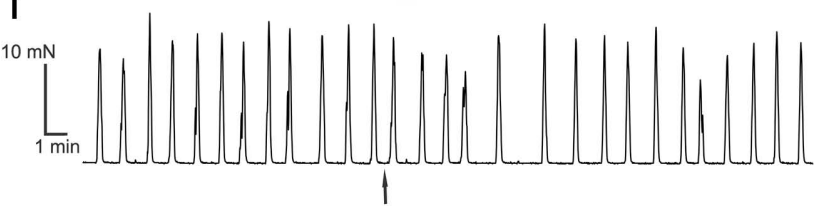

FIGURE 3 |Are rhythmic propulsive motor complexes neurogenic? Spatiotemporal maps $(\mathbf{A}, \mathbf{C}, \mathbf{E}, \mathbf{G})$ and corresponding intraluminal pressure recordings [(B,D,F,H) respectively] of the same preparations under control conditions (A,B), $100 \mu \mathrm{M}$ lidocaine (C,D), $100 \mu \mathrm{M}$ lidocaine $+1 \mu \mathrm{M}$ carbachol (E,F) and $100 \mu \mathrm{M}$ lidocaine $+4 \mu \mathrm{M}$ carbachol (G,H). (I) Stretch evoked contractions of rat colon circular muscle strips in vitro (muscle bath), occurring at the same frequency as the rhythmic propulsive motor complexes, were not influenced by the addition of $100 \mu \mathrm{M}$ lidocaine (added at arrow). 
One of the reasons to call the first motor pattern "rhythmic propulsive motor complexes" was that the rhythmic propagating ripples were most often seen as part of the motor complex. The two motor patterns appeared additive. When the rhythmic propagating ripples propagated "into" the propulsive motor complex, the amplitude of the ripples increased (Figures 2A,C). Hence, on the one hand, the direction of propagation of the rhythmic propagating ripples was independent of the rhythmic propulsive motor complexes suggesting that they were controlled by different control systems. On the other hand, there was a clear interaction: when one follows a propagating ripple in Figure 2A, one sees that the amplitude of the ripple increases when overlap with the rhythmic propulsive motor complexes occurs, only to reduce strongly in amplitude when the overlap ends.

\section{ARE THE RHYTHMIC PROPULSIVE MOTOR COMPLEXES NEUROGENIC?}

Lidocaine $(100 \mu \mathrm{M})$ or TTX $(0.2 \mu \mathrm{M})$, blockers of neuronal sodium channels, blocked rhythmic propulsive motor complexes in the mid colon and inhibited but did not abolish them in the proximal colon (Figure 3). The fact that rhythmic propulsive motor complexes often continued in the proximal colon indicated that neural input provided a dominant stimulus but was not essential for this motor pattern. We reasoned that if the ENS provided a stimulus but was not the pattern generator, then mimicking this stimulus by a muscarinic agonist, might restore this motor pattern in the presence of ENS block. This was indeed what happened. In the presence of lidocaine, carbachol $(1-2 \mu \mathrm{M})$ induced rhythmic propulsive motor complex (Figures 3G-H). The frequency of propulsive motor complexes in the mid colon was in fact greater than under control conditions $(0.8 \pm 0.2 / \mathrm{min}$ versus $0.5 \pm 0.1 / \mathrm{min})$ and the complexes extended into the distal colon.

Rhythmic propulsive motor complexes were also abolished by atropine ( $2 \mu \mathrm{M}, n=3$; not shown) indicating that the primary neural stimulus comes from cholinergic motor neurons under our experimental conditions. Conversely $200 \mu \mathrm{M}$ L-NNA, a blocker of nitric oxide synthesis increased the complex frequency from $0.5 \pm 0.2$ to $0.8 \pm 0.2 / \min (n=5)$.

Hence although rhythmic propulsive motor complexes as well as rhythmic propagating ripples have their pattern generator outside the ENS, the expression of rhythmic propulsive motor complexes is controlled by a balance of inhibitory nitrergic and excitatory cholinergic inputs from the ENS in the whole colon in vitro and likely in vivo as well. This should be reflected by physical interaction of ICC networks and the ENS.

\section{INTERACTION OF THE TWO ICC NETWORKS WITH THE ENS}

Both ICC-MP (Figure 4A) and ICC-SMP (Figure 4C) in the rat colon are dense networks of multipolar, stellate, occasionally elongated cells. The ICC-SMP network is embedded in the submucosa at the edge of the inner circular muscle. The two networks do not appear to be connected to each other (Figure 4B). Since our hypothesis requires cholinergic innervations of ICC-MP, we carried out co-staining of c-Kit to identify ICC and VAChT to identify cholinergic nerves in the rat and mouse colons. According to their shape, most of the VAChT positive structures are axon varicosities within nerve strands and ganglia (Figures 4D-F). ICC-MP follow closely the outline of VAChT positive nerve strands (Figures $4 \mathrm{D}, \mathrm{F}$ ) and the myenteric ganglia containing VAChT positive nerves (Figure 4E).
They also closely appose individual cholinergic nerve varicosities at the level of myenteric plexus (Figures 4D,F). Bipolar shaped intramuscular ICC (ICC-IM; Figure 4G) were also intimately associated with the cholinergic nerves in both muscle layers.

\section{DEVELOPMENT OF THE HYPOTHESIS}

We propose that rhythmic propagating ripples have the ICC-SMP network as pacemaker. This pattern is not markedly changed by lidocaine or carbachol and appears to be the equivalent to the TTX resistant "high frequency, low amplitude contractions" Pluja et al. (2001) recorded from muscle strips. This activity was only observed when ICC-SMP were attached to the muscle and its electrical counterpart was recorded as omnipresent slow wave activity (Pluja et al., 2001). Similar electrical activity was linked to ICC-SMP in the mouse colon (Yoneda et al., 2002). These ripples will disturb colonic content at the mucosal surface thereby likely optimizing absorption. The contractions are not reflected in marked changes in intraluminal pressure and are not associated with outflow of content, that is: when not associated with the ICC-MP pacemaker, see below. Therefore ripple contractions may not be characterized as performing peristalsis.

We propose that rhythmic propulsive motor complexes have the ICC-MP as pacemaker and not the ENS. This is based on the following experimental observations, taken together.

1. In the proximal colon rhythmic propulsive motor complexes were inhibited but not abolished by TTX or lidocaine. This means that in the proximal colon their existence and propagation do not require active neurons.

2. In the mid colon rhythmic propulsive motor complexes were blocked by TTX and lidocaine but when another stimulus (carbachol) was introduced, they resumed with characteristics identical to that before neural blockade. This strongly suggests that under control conditions the nervous system supplied the stimulus but was not the mechanism creating the rhythmicity.

3. The rhythmic propulsive motor complexes occur at a frequency of $\sim 1 / \mathrm{min}$. In muscle strips, high amplitude contractions of the circular muscle occur at a similar frequency. These contractions are dependent on muscle stretch and under stretch occur in the presence of lidocaine or TTX indicating that in vitro, muscle stretch is a sufficient stimulus.

4. In muscle strips, the equivalent of the rhythmic propulsive motor complexes are only present when the ICC-MP are intact (Pluja et al., 2001). In the mouse colon, rhythmic propulsive motor complexes ("CMMCs") can be recorded after removal of the mucosa, submucosa, and submuscular plexus (Keating and Spencer, 2010b). This is consistent with the proposed role of ICC-MP.

5. In vitro, the equivalent of the rhythmic propulsive motor complexes are associated with rhythmic transient depolarizations (Pluja et al., 2001; Powell et al., 2003). These depolarizations are dependent on L-type calcium channel activity (Pluja et al., 2001), indicating that they are stimulus-dependent (similar to the guinea pig small intestine Donnelly et al., 2001) since they require depolarization above threshold for L-type calcium channel activation. 

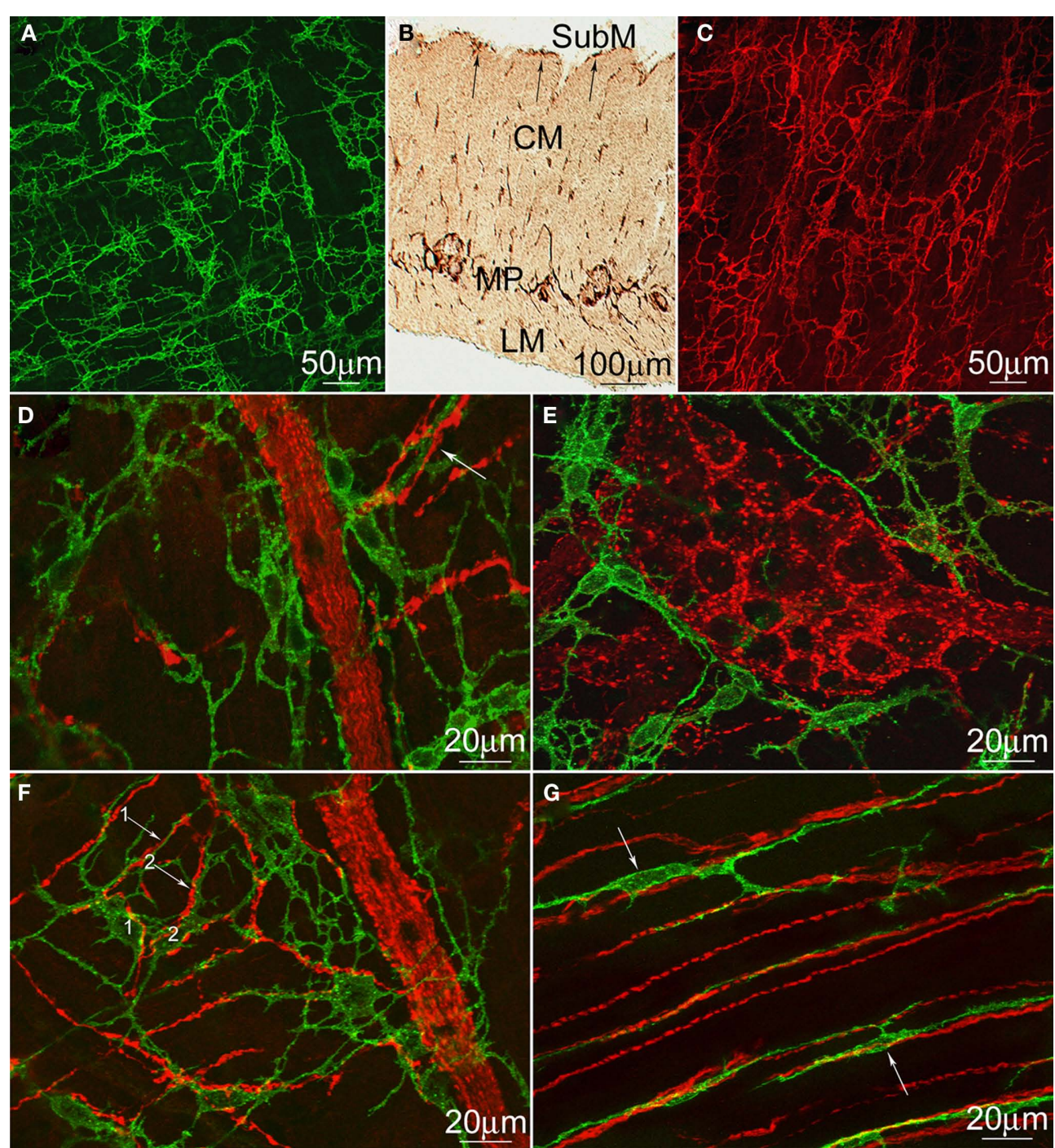

FIGURE 4 | Distribution of rat and mouse colonic ICC and cholinergic neurons. c-Kit immunostaining of ICC-MP (A) and ICC-SMP (C) in wholemounts of the rat colon and a cross-section (B). LM, longitudinal muscle; MP, myenteric plexus; CM, circular muscle; SubM, submucosa. Both ICC-SMP and ICC-MP form dense networks at the level of the submuscular plexus and the myenteric plexus respectively. ICC-SMP run parallel to the circular muscle layer. (D-G) Double immunostaining of VAChT (red) and c-Kit (green) to show the cholinergic nerves and ICC-MP (D-F) or ICC-IM (G) in whole-mounts of the rat $(\mathbf{D}, \mathbf{E})$ and mouse $(\mathbf{F}, \mathbf{G})$ colons. ICC-IM closely align the boundaries of myenteric ganglia (E) or nerve strands (D,F). All arrows indicate intimate contacts between ICC processes and cholinergic nerves. In (F), two processes (arrows \#1 and \#2) from two mouse ICC-MP cell bodies (labeled as 1 and 2), respectively, are closely associated with two cholinergic nerves at the level of myenteric plexus.
The proposal is that intrinsic rhythmic depolarizations from the ICC-MP underlie the rhythmic propulsive motor complexes, and that this electrical activity is responsible for the propagating nature of the contractions. Interestingly, the rhythmic activity appears to have a frequency gradient. In vitro, the contractions had a much higher frequency in proximal strips compared to distal strips (Alberti et al., 2005). In fact, this frequency gradient has been observed measuring equivalent electrical activity in vivo (Ferre and Ruckebusch, 1985), or propagating contractions measured by strain gages ( $\mathrm{Li}$ et al., 2002). It is therefore possible that the mechanism of propagation is similar to that of slow wave propagation in the small intestine which is based on the existence of a frequency gradient (Diamant and Bortoff, 1969). The origin of a propagating contraction is the site of the highest frequency slow wave that paces neighboring activity. When mouse colonic CMMC's were interrupted in the mid colon by nerve blockade, they appeared in the distal colon at a reduced frequency (Powell et al., 2002).

For decades, certain propagating rhythmic motor patterns in the colon have been described as either neurogenic (blocked by TTX) or myogenic (insensitive to TTX). When motor activities are abolished by TTX, it is usually assumed or stated by the investigators that the ENS controls occurrence, rhythmicity, and propagation, although no evidence other than TTX sensitivity is usually provided. In some cases, similar contraction patterns appeared neurogenic in vivo or ex vivo but myogenic in vitro (Gonzalez and Sarna, 2001b; Li et al., 2002). We now give an explanation for this apparent contradiction, 
bringing the interpretation to a consensus in that motor patterns are generated by ICC pacemaker activity that is dependent on a stimulus, the stimulus being provided predominantly by the ENS in vivo. The fact that such motor activities are not abolished by TTX in vitro is explained by the notion that neural activity is not the only possible stimulus that can evoke the motor pattern; stretch and activation of muscarinic receptors being two other potential stimuli. Recently strong evidence for the neural induction of pacemaker activity in ICC-MP was provided using simultaneous calcium imaging in nerve varicosities and ICC-MP (Bayguinov et al., 2010b). During an evoked rhythmic propulsive motor complex, calcium transients appeared in nerve varicosities overlying ICC-MP, followed by relatively long but transient calcium increases in ICC (Bayguinov et al., 2010b; see also Figure 5), which was followed by calcium transients in smooth muscle (Bayguinov et al., 2010b).
Based on the electrophysiological work from the laboratory of Jimenez in vitro on the rat colon (Pluja et al., 2001; Alberti et al., 2007) ICC-SMP generate slow waves that cause rhythmic depolarization of smooth muscle cells, leading to rhythmic propulsive ripples under un-stimulated conditions. Slow waves can propagate in either an oral or anal direction, usually over short distances. The ICC-MP generate rhythmic transient depolarizations that propagate in anal direction. This happens only after excitatory stimulation that can be evoked by distention alone, by activity of the ENS or by pharmacological means (such as a muscarinic agonist). The frequency and amplitude of the rhythmic depolarization is likely to be highly variable because it will depend on stimulus strength.

Slow waves (ripples) and rhythmic transient depolarizations (motor complexes) are independently controlled since the presence of one is not dependent on the other and they can propa-

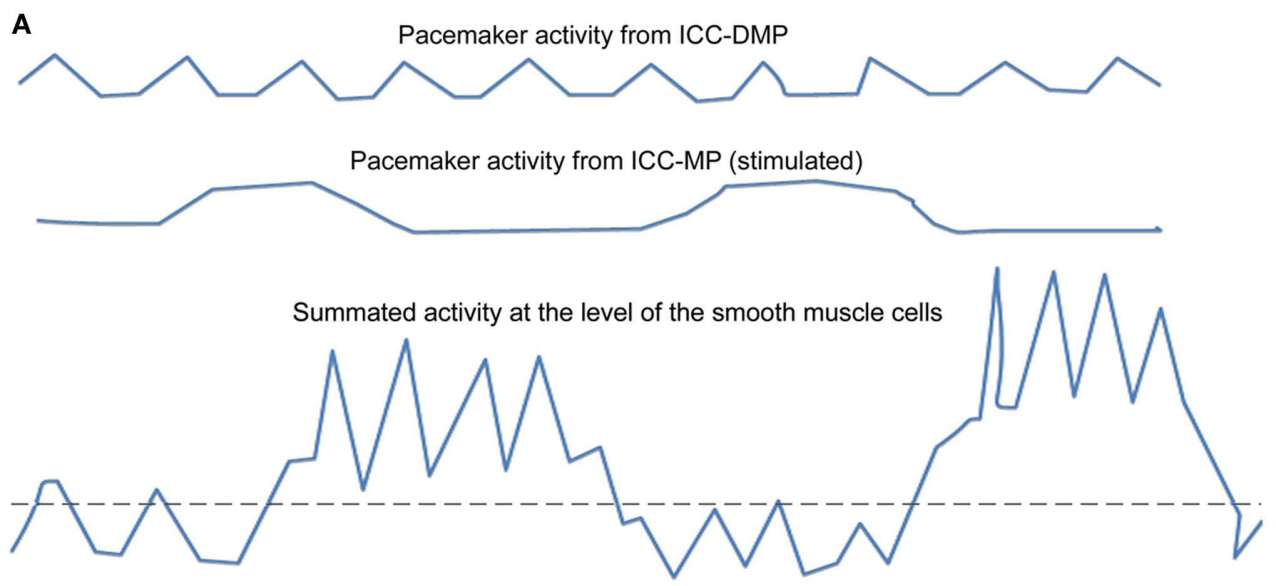

B

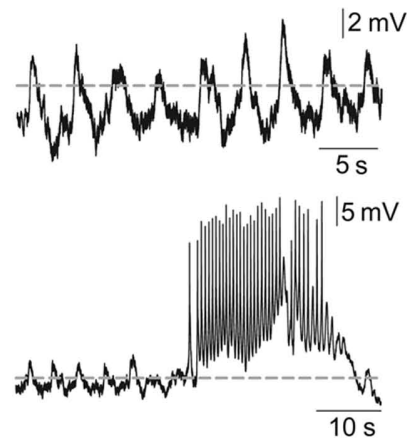

C

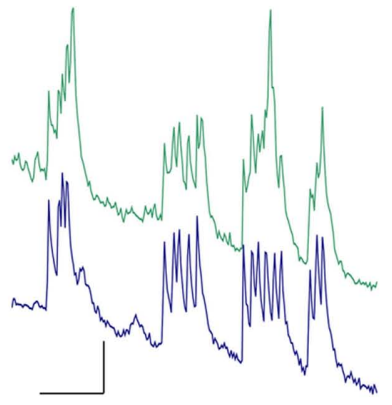

D
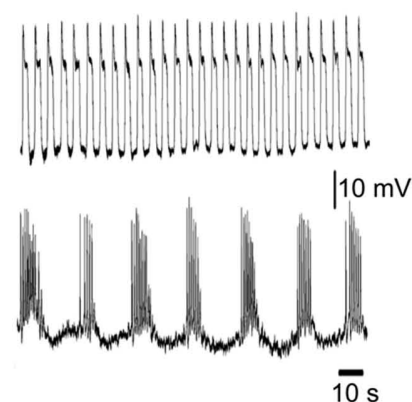

FIGURE 5 | Schematic drawing of the proposed electrophysiological basis of the rhythmic propulsive motor complexes. (A) Smooth muscle cells of the colon may only receive slow wave activity propagated from ICC-SMP (top line). This may be associated with small amplitude contractions if the slow waves barely pass threshold (dotted line) for generation of action potentials dependent on activation of L-type calcium channels. When the rhythmic transient depolarizations hypothesized to come from ICC-MP under stimulated conditions (middle line) are also received by the smooth muscle cells, de cells will obviously rhythmically depolarize and the slow waves will be pushed well above the threshold and hence action potentials and hence contractions may become much more prominent. (B) Actual electrical recordings from the rat colon circular muscle, modified from previously published figures (Pluja et al., 2001). Top line shows slow waves originating from ICC-SMP, bottom line shows in addition a transient depolarization coming from ICC-MP. (C) Synchronized rhythmic calcium transients from two ICC-MP of the mouse colon (Lowie and Huizinga, unpublished). Y-axis are in arbitrary units, the $\mathrm{X}$-axis bar $=5 \mathrm{~s}$. (D) Activity recorded from circular muscle associated with ICC-SMP of the mouse colon (top line) and activity recorded from a longitudinal smooth muscle cell probably influenced by ICC-MP; modified figure from (Yoneda et al., 2004). 
gate in opposing directions. They appear to be additive in terms of contraction and this also appears to be the case for muscle depolarization (Pluja et al., 2001). This suggests that the muscle has a graded contractile response to depolarization. This graded response is likely related to the extent to which the smooth muscle cells are above threshold for generation of L-type calcium channel dependent action potentials (Figure 5). In addition, graded responses could be associated with non-uniform thresholds and/or heterogeneous resting membrane potentials. The latter is particularly likely since there is significant evidence for the resting membrane potential being graded along the thickness of the muscle wall (Liu and Huizinga, 1993; Sha et al., 2007). In addition to the electrical activities received from both networks of ICC, the smooth muscle cells can receive directly excitatory (depolarization) and inhibitory (hyperpolarization) stimuli from the ENS or from blood born substances.

\section{DISCUSSION}

All published studies involving rhythmic propulsive motor complexes as discussed here propose that they are orchestrated by the ENS. Our interpretation is that the motor complexes are indeed dependent on neural activity, but that the dependency lies in neurally dependent excitation of the ICC-MP and concomitant neuralexcitation of the smooth muscle. Hence we propose that it is the ICC-MP pacemaker activity that provides the rhythmicity.

ICC-MP in the colon associate with cholinergic nerves of the myenteric plexus. Although synapse-like connections were not observed when we studied this at the ultrastructural level, the intimate relationship between ICC-MP and VAChT positive nerve endings suggests extensive functional cholinergic innervation of ICC-MP. Indeed, this has recently been demonstrated using calcium imaging in the network of ICC-MP (Bayguinov et al., 2010b).

Peristaltic propulsive motor complexes are often thought to be associated with the "peristaltic reflex." That is: oral excitation and anal relaxation relative to a focal stimulus. That this classical reflex occurs is beyond question and has been demonstrated by balloon distention (Spencer and Smith, 2001) in the guinea pig distal colon. However, much of colonic motility is not evoked by point excitation but by more general excitation due to distention of a larger section of the colon filled with content. This will give a maintained stimulus and not a transient stretch stimulus. And even pellets can produce a maintained stimulus. Smith et al. (2003) wrote: "the observation that a fixed maintained stimulus can evoke these rhythmic peristaltic waves may seem unusual since enteric neural reflex stimulation of the colon usually evoked a phasic response." Are TTX sensitive motor patterns in the colon necessarily evoked by a reflex? Similar to the guinea pig ileum (Spencer et al., 1999), the "law of the intestine" is unlikely to be responsible for the rhythmic propulsive motor complexes in the colon. Rhythmic propulsive motor complexes in the colon that are abolished by TTX, could have their origin in (1) Rhythmic transients depolarizations in smooth muscle cells that are evoked by rhythmically firing excitatory nerves. (2) A myogenic slow wave that does not reach threshold for generation of contraction, and is elevated by activity of enteric nerves on smooth muscle cells. (3) Neural-excitation evoked pacemaker activity in a latent ICC pacemaker network in addition to neural and/or stretch evoked excitation to smooth muscle. We propose that the studies discussed here on the colon provide data that is most consistent with the third option. Why would the nervous system not provide the rhythmicity? The ENS can generate rhythmic motor patterns, since it is the primary regulator of the MMC in the small intestine, the rhythmic motor activity that occurs during fasting. However, the rhythmic propulsive motor complexes in the colon described here, occur at a much faster frequency, are not restricted to fasting, and can be recorded in the presence of TTX. In addition, no rhythmic neural activity has been recorded in myenteric ganglia, whereas the capability of ICC networks to produce rhythmic activities has been demonstrated numerous times. Wood suggests the existence of burst-type neurons that are endogenous oscillators (Wood, 1975) but electrophysiological data to support that rhythmic motor complexes in the colon are associated with neuronal pacemaker activity has not been forth coming.

\section{IN VIVO VERSUS IN VITRO}

The rhythmic propulsive motor complexes in the rat colon occur in vivo at 0.6 contraction $/ \mathrm{min}$ and are inhibited by atropine or hexamethonium to $\sim 0.05 / \mathrm{min}$ in the proximal colon; in the distal colon they occur at $0.2 / \mathrm{min}$ and they disappear with these drugs (Li et al., 2002). The usual interpretation of such findings is that the motor complexes are neurogenic. However, when these motor complexes are evoked in muscle strips, their amplitude is actually enhanced by TTX and the frequency is increased from 0.2 to 0.8 contractions/min, whereas atropine does not have a significant effect (Gonzalez and Sarna, 2001b). These numbers are the same for the effect of L-NNA in vitro suggesting that the main effect of TTX is due to inhibition of nitrergic neurons. But clearly, the cholinergic nerves are also blocked hence there is no need for cholinergic nerve activity in vitro. In the present experiments, in a whole segment of rat colon in vitro, TTX, and lidocaine abolished the motor complexes in the mid and distal colon, but not in the proximal colon. Why these differences? The in vitro muscle strips still contain the ENS of course and electrical field stimulation can activate inhibitory and excitatory motor neurons. Yet the neural stimulus has lost its dominance over the stretch or tension stimulus as seen in vivo. One likely explanation is that the stimulus from the ENS only works optimally when the circuitry is intact circumferentially, likely because the $\mathrm{AH}$ sensory nerves are oriented circumferentially (Kunze and Furness, 1999). Gonzalez and Sarna (2001b) suggested that stretch in vitro is able to trigger the same cellular mechanism as ACh does in vivo. Indeed, that mechanism could be stretch- or neurally-evoked pacemaker activity in ICC-MP.

\section{STIMULUS DEPENDENCY}

Recently an interesting debate took place in the pages of Gastroenterology on controversies about the control of cyclic motor activity in the colon, between the laboratories of Terry Smith (Smith et al., 2010) and Nick Spencer (Keating and Spencer, 2010a) both working on the mouse colon. We believe that our theory can handily incorporate the scientific findings from both groups and alleviate the apparent contradictory results of these two outstanding laboratories. At the heart of the debate is the statement by Keating and Spencer that $5 \mathrm{HT}$ released from enterochromaffin cells are not required for generation and propagation of CMMCs. We agree with this statement. In our hands in both 
the rat colon (documented here) and the mouse colon (Jimenez, unpublished) the rhythmic motor complexes occur unabated in mucosa free preparations. We also agree with the statement by Keating and Spencer that "the intrinsic pacemaker and pattern generator underlying the CMMC generation and propagation is located within the myenteric plexus and/or the muscularis externa," although we consider it interesting that not even consideration is given to the ICC network that lies within the myenteric plexus of the guinea pig colon, a network that is designed for pacemaking and propagation. Smith et al. (2010) basically agree with the statement that $5 \mathrm{HT}$ is not required [despite the fact that a letter to the editor was sent to contradict Keating and Spencer's (2010b) study] since they have shown that stretch evoked CMMCs are not blocked by ondansetron and CMMC's can be evoked electrically in mucosa free preparations. Smith and coworkers point out that 5HT from enterochromaffin cells is involved in the initiation of CMMCs by brushing the mucosa (Bayguinov et al., 2010a); we do not think that there is any disagreement about this. The main reason why our hypothesis encompasses the data from both groups is that we stress that at the heart of the CMMCs (which we call here rhythmic propulsive motor complexes mainly because we believe them to be fundamentally different from the fasting MMCs of the small intestine) are the stimulus-dependent rhythmic depolarizations generated by the ICC-MP within the myenteric plexus. Our point is that this stimulus can be many things: stretch via a pellet, distention over a length of the colon, stretch in the presence of TTX in muscle strips, pharmacological means such as activation of muscarinic receptors. It is possible that $5 \mathrm{HT}$ is essential for some of these stimuli such as mucosal stroking. Smith and coworkers come close to our hypothesis when they conclude that "CMMC generation cannot be considered just a neural event but a synergistic interaction between neural and ICC networks" (Dickson et al., 2010). However, they link the ICC-MP to the fast oscillations and the "slow-depolarization" to muscarinic and NK1 receptor activation on smooth muscle. Our evaluation of the literature and our own work leads to the proposal that the slow transient depolarizations carrying the CMMCs in the mouse or the rhythmic propulsive motor complexes described here in the rat colon are generated by ICC-MP.

If our hypothesis is correct, the extrinsic neural mechanisms (i.e., gastrocolonic reflexes, stress etc.) that cause an increase in the frequency of propulsive contractions in the rat colon should converge in an increase of the release of acetylcholine acting on ICC increasing the frequency (ICC) and force (smooth muscle) of contractions. In contrast extrinsic neurons converging in activation of inhibitory neurons might cause decreased frequency of contractions (NO-ICC) or even phasic smooth muscle hyperpolarization and relaxation (NO/ATP-smooth muscle; Gil et al., 2010).

The membrane potential gradient in the colon is such that in intact tissue, the smooth muscle cells bordering the submucosa are more hyperpolarized compared to those at the myenteric plexus as shown in the dog (Smith et al., 1987; Liu and Huizinga, 1993) and mouse colon (Sha et al., 2010). In the stomach, the ICC network associated with the myenteric plexus border is the most hyperpolarized (Bauer and Sanders, 1985). It is likely that it is a network of ICC that pulls the membrane potential down, likely via CO synthesis (Sha et al., 2007) although in the mouse colon submucosal nerves may be involved (Sha et al., 2010). Interestingly, the ICC network that is doing the pulling, in the colon, stomach, and intestine, is the one that generates the omnipresent slow wave. This has the advantage that under most conditions, it is the slow wave plateau that surpasses the mechanical threshold securing phasic contractile activity and never the resting membrane potential that is too hyperpolarized. It is possible that as a protective mechanism against unwanted contractile activity, the ICC-SMP remain hyperpolarized by CO, whereas the ICC-MP have nifedipine sensitive slow waves, hence they do not occur in any case below the threshold for activation of L-type calcium channels.

\section{RAT COLON COMPARED TO OTHER SPECIES}

The mouse colon has similar activity as the rat colon (Lyster et al., 1995). The cyclic depolarizations are sometimes referred to as "classical slow waves," but they are nifedipine sensitive hence they are stimulus-dependent and therefore not "classical" slow waves (Zhang et al., 2010). The hypothesis presented here for the rat colon is entirely consistent with the data and discussion presented by Takaki and coworkers on the mouse colon (Yoneda et al., 2004). Although the guinea pig is often considered to be "slow wave free," stimulusdependent slow wave activity is clearly present in the guinea pig small intestine (Donnelly et al., 2001) and is likely to occur in the ICC of the guinea pig colon (Komuro, 2006). The human colon exhibits a relatively strong electrical rhythmic activity from 3 to $12 / \mathrm{min}$ but also a much slower rhythm that has superimposed high frequency oscillations and action potentials and this appears to be associated with a strong motor activity at a frequency of $1-3 / \mathrm{min}$ (Bueno et al., 1980 b). We speculate that in the human colon, transient depolarizations that must underlie the bursts of action potentials (Bueno et al., 1980b) and/or rhythmic propulsive contractions (Dinning et al., 2010) are generated by ICC-MP, similar to the rat colon.

\section{THE COLON, COMPARED TO OTHER GUT ORGANS}

Is the proposed hypothesis on stimulus-dependent ICC pacemaker activity in the colon applicable to other organs of the gut? The esophagus does not normally present with rhythmic contractile activity but, at least in vitro, can easily be evoked to do so. In the cat, muscarinic stimulation can evoked slow wave activity that is accompanied by peristalsis (Preiksaitis and Diamant, 1999). Since ICC-MP are rare in the cat esophagus (Huizinga et al., 2008b) but ICC-IM are numerous, it may be speculated that ICC-IM are related to the generation of the slow waves. ICC-IM are closely linked to vagal nerves which might provide the stimulus, possibly by blocking aminacrine-sensitive K channels (Walton and Huizinga, 1989).

In the stomach there is strong evidence for interactions between ICC-MP and ICC-IM (Edwards and Hirst, 2005; Hirst and Edwards, 2006), and it appears that cooperation between the two pacemaker networks generates the one dominant stomach motor activity, anally directed peristalsis. Whether both of the networks have intrinsic and/or stimulus-dependent pacemaker activity has not been carefully assessed. Interestingly whereas the fundus is rarely considered to harbor pacemaker activity, recent reports show burst-type transient depolarizations associated with fundic ICC-IM in the rat (Kito et al., 2009) and the origin of pacemaking in the canine stomach was shown to be in the upper fundus (Lammers et al., 2009). 
Similar to the colon, the small intestine has an ICC network associated with the myenteric plexus as well as one at the border of the submucosa albeit just inside the circular muscle layer, hence called ICC-DMP. A role for ICC-DMP in pacemaking has been suggested rarely. A study in the canine ileum by Jimenez et al. (1996) recorded "triangular" depolarizations from crosssectioned preparations at the level of the DMP. This electrical activity appeared independent from the slow wave activity generated by ICC-MP. In the cat intestine, acetylcholine-induced slow waves have been reported to occur in early studies (Dahms et al., 1987) and Bolton has extensively studied acetylcholine-induced slow waves in the guinea pig ileum (Bolton, 1971). Interestingly rhythmic low and high frequency propagating motor activity is very often encountered (Ehrlein et al., 1987; Nieuwmeyer et al., 2006) and we have preliminary data that suggests that the proposed theory of independent but cooperating ICC pacemaker systems may also apply to the small intestine (Huizinga and Kunze, unpublished).

\section{REFERENCES}

Alberti, E., Mikkelsen, H. B., Larsen, J. O., and Jimenez, M. (2005). Motility patterns and distribution of interstitial cells of Cajal and nitrergic neurons in the proximal, mid- and distal-colon of the rat. Neurogastroenterol. Motil. 17, 133-147.

Alberti, E., Mikkelsen, H. B., Wang, X. Y., Diaz, M., Larsen, J. O., Huizinga, J. D., and Jimenez, M. (2007). Pacemaker activity and inhibitory neurotransmission in the colon of Ws/Ws mutant rats. Am. J. Physiol. Gastrointest. Liver Physiol. 292, G1499-G1510.

Barajas-Lopez, C., and Huizinga, J. D. (1989). Different mechanisms of contraction generation in circular muscle of canine colon. Am. J. Physiol. 256, G570-G580.

Bauer,A. J., Publicover, N. G., and Sanders, K. M. (1985). Origin and spread of slow waves in canine gastric antral circular muscle. Am. J. Physiol. 249, G800-G806.

Bauer, A. J., and Sanders, K. M. (1985). Gradient in excitation-contraction coupling in canine gastric antral circular muscle. J. Physiol. (Lond.) 369, 283-294.

Bayguinov, P. O., Hennig, G. W., and Smith, T. K. (2010a). Calcium activity in different classes of myenteric neurons underlying the migrating motor complex in the murine colon. J. Physiol. (Lond.) 588, 399-421.

Bayguinov, P. O., Hennig, G. W., and Smith, T. K. (2010b). Ca2+ imaging of activity in ICC-MY during local mucosal reflexes and the colonic migrating motor complex in the murine large intestine. J. Physiol. (Lond.) 588, 4453-4474.
Beckett, E. A., Takeda, Y., Yanase, H., Sanders, K. M., and Ward, S. M. (2005). Synaptic specializations exist between enteric motor nerves and interstitial cells of Cajal in the murine stomach. J. Comp. Neurol. 493, 193-206.

Bolton, T. B. (1971). On the nature of the oscillations of the membrane potential (slow waves) produced by acetylcholine or carbachol in intestinal smooth muscle. J. Physiol. (Lond.) 216, 403-418.

Bueno, L., Fioramonti, J., Frexinos, J., and Ruckebusch, Y. (1980a). Colonic myoelectrical activity in diarrhea and constipation. Hepatogastroenterology 27, 381-389.

Bueno, L., Fioramonti, J., Ruckebusch, Y., Frexinos, J., and Coulom, P. (1980b). Evaluation of colonic myoelectrical activity in health and functional disorders. Gut 21, 480-485.

Burns, A. J., Lomax, A. E., Torihashi, S., Sanders, K. M., and Ward, S.M. (1996). Interstitial cells of Cajal mediate inhibitory neurotransmission in the stomach. Proc. Natl. Acad. Sci. U.S.A. 93, 12008-12013.

Chow, E., and Huizinga, J. D. (1987). Myogenic electrical control activity in longitudinal muscle of human and dog colon. J. Physiol. (Lond.) 392, 21-34.

Dahms, V., Prosser, C. L., and Suzuki, N. (1987). Two types of "slow waves" in intestinal smooth muscle of cat. $J$. Physiol. 392, 51-69.

D’Antona, G., Hennig, G. W., Costa, M., Humphreys, C. M., and Brookes, S. J. (2001). Analysis of motor patterns in the isolated guinea-pig large intestine by spatio-temporal maps. Neurogastroenterol. Motil. 13,483-492. Der-Silaphet, T., Malysz, J., Hagel, S., Larry Arsenault, A., and Huizinga,

In summary, evidence that the world of the ENS and the world of ICC are inextricably intertwined is unrelentingly marching forward. To proof that the ICC-MP generate stimulus-dependent pacemaking that governs a dominant propulsive motor activity in the colon studies on ICC-MP, more molecular, electrophysiologi$\mathrm{cal}$, and functional studies need to be done on this ICC network.

\section{ACKNOWLEDGMENTS}

A CIHR operating grant to Huizinga provided financial support. The Farncombe Family Digestive Health Research Institute provided partial support for Sarah Martz. Marc Pistilli provided the in vitro muscle strip data used in Figure 3. Victor Gil was supported by the Ministerio de Educación y Ciencia (Spain) AP2007-01583 Marcel Jimenez obtained operating funds from grant BFU2009-11118. This paper was presented and discussed at a 1-day workshop "Peristalsis and propulsive movements in the gut" in Boston, USA, organized by Terrence Smith and Raj Goyal on August 26-29, 2010.

J. D. (1998). Interstitial cells of Cajal direct normal propulsive contractile activity in the mouse small intestine. Gastroenterology 114, 724-736.

Diamant, N. E., and Bortoff, A. (1969) Nature of the intestinal low-wave frequency gradient. Am. J. Physiol. 216, 301-307.

Dickson, E. J., Heredia, D. J., McCann, C. J., Hennig, G. W., and Smith, T. K. (2010). The mechanisms underlying the generation of the colonic migrating motor complex in both wild-type and nNOS knockout mice. Am. J. Physiol. Gastrointest. Liver Physiol. 298, G222-G232.

Dickson, E. J., Spencer, N. J., Hennig, G. W., Bayguinov, P. O., Ren, J., Heredia, D. J., and Smith, T. K. (2007). An enteric occult reflex underlies accommodation and slow transit in the distal large bowel. Gastroenterology 132, 1912-1924.

Dinning, P. G., Szczesniak, M. M., and Cook, I. J. (2008). Twenty-four hour spatiotemporal mapping of colonic propagating sequences provides pathophysiological insight into constipation. Neurogastroenterol. Motil. 20, 1017-1021.

Dinning, P. G., Zarate, N., Hunt, L. M. Fuentealba, S. E., Mohammed, S. D., Szczesniak, M. M., Lubowski, D. Z., Preston, S. L., Fairclough, P. D., Lunniss, P. J., Scott, S. M. and Cook, I. J. (2010). Pancolonic spatiotemporal mapping reveals regional deficiencies in, and disorganization of colonic propagating pressure waves in severe constipation. Neurogastroenterol. Motil. 22, e340-e349.

Donnelly, G., Jackson, T. D., Ambrous, K., Ye, J., Safdar, A., Farraway, L., and Huizinga, J. D. (2001). The myogenic component in distention-induced peristalsis in the guinea pig small intestine. Am. J. Physiol. Gastrointest. Liver Physiol. 280, G491-G500.

Du, C., Ferre, J. P., and Ruckebusch, Y. (1987). Spinal cord influences on the colonic myoelectrical activity of fed and fasted rats. J. Physiol. 383, 395-404.

Edwards, F. R., and Hirst, G. D. (2005). An electrical description of the generation of slow waves in the antrum of the guinea-pig. J. Physiol. (Lond.) 564, 213-232.

Ehrlein, H. J., Schemann, M., and Siegle, M. L. (1987). Motor patterns of small intestine determined by closely spaced extraluminal transducers and video fluoroscopy. Am. J. Physiol. 253, G259-G267.

Faussone-Pellegrini,M.S., Cortesini,C., and Romagnoli, P. (1977). Ultrastructure of the tunica muscularis of the cardial portion of the human esophagus and stomach, with special reference to the so-called Cajal's interstitial cells. Arch. Ital. Anat. Embriol. 82, 157-177.

Faussone-Pellegrini, M. S. (2006). Relationships between neurokinin receptor-expressing interstitial cells of Cajal and tachykininergic nerves in the gut. J. Cell. Mol. Med. 10, 20-32.

Ferre, J. P., and Ruckebusch, Y. (1985). Myoelectrical activity and propulsion in the large intestine of fed and fasted rats. J. Physiol. (Lond.) 362, 93-106.

Fida, R., Lyster, D. J., Bywater, R. A., and Taylor, G.S. (1997). Colonic migrating motor complexes (CMMCs) in the isolated mouse colon. Neurogastroenterol. Motil. 9, 99-107.

Fioramonti, J., Garcia-Villar, R., Bueno, L., and Ruckebusch, Y. (1980). Colonic myoelectrical activity and 
propulsion in the dog. Dig. Dis. Sci. $25,641-646$.

Fox, E. A., Phillips, R. J., Martinson, F. A., Baronowsky, E. A., and Powley, T. L. (2000). Vagal afferent innervation of smooth muscle in the stomach and duodenum of the mouse: morphology and topography. J. Comp. Neurol. $428,558-576$.

Furuzono, S., Nakayama, S., and Imaizumi, Y. (2005). Purinergic modulation of pacemaker $\mathrm{Ca} 2+$ activity in interstitial cells of Cajal. Neuropharmacology 48, 264-273.

Gil, V., Gallego, D., Grasa, L., Martin, M. T., and Jimenez, M. (2010). Purinergic and nitrergic neuromuscular transmission mediates spontaneous neuronal activity in the rat colon. Am. J. Physiol. Gastrointest. Liver Physiol. 299, G158-G169.

Gonzalez, A., and Sarna, S. K. (2001a). Different types of contractions in rat colon and their modulation by oxidative stress. Am. J. Physiol. Gastrointest. Liver Physiol. 280, G546-G554.

Gonzalez, A., and Sarna, S. K. (2001b). Neural regulation of in vitro giant contractions in the rat colon. Am. J. Physiol. Gastrointest. Liver Physiol.281, G275-G282.

Goyal, R. K., and Chaudhury, A. (2010). Mounting evidence against the role of ICC in neurotransmission to smooth muscle in the gut. Am. J. Physiol. Gastrointest. Liver Physiol. 298, G10-G13.

He, C.L., Burgart, L., Wang, L., Pemberton, J., Young-Fadok, T., Szurszewski, J., and Farrugia, G. (2000). Decreased interstitial cell of Cajal volume in patients with slow-transit constipation. Gastroenterology 118, 14-21.

Hennig, G. W., Costa, M., Chen, B. N., and Brookes, S. J. (1999). Quantitative analysis of peristalsis in the guineapig small intestine using spatio-temporal maps. J. Physiol. (Lond.) 517, 575-590.

Hirst, G. D., and Edwards, F. R. (2006). Electrical events underlying organized myogenic contractions of the guinea pig stomach. J. Physiol. (Lond.) 576, 659-665.

Hirst, G. D., Garcia-Londono, A. P., and Edwards, F. R. (2006). Propagation of slow waves in the guinea-pig gastric antrum.J. Physiol. (Lond.) 571, 165-177.

Huizinga, J. D., Chang, G., Diamant, N. E., and El-Sharkawy, T. Y. (1984). Electrophysiological basis of excitation of canine colonic circular muscle by cholinergic agents and substance P. J. Pharmacol. Exp. Ther. 231, 692-699.

Huizinga, J. D., Golden, C. M., Zhu, Y., and White, E. J. (2004). Ion channels in interstitial cells of Cajal as targets for neurotransmitter action. Neurogastroenterol. Motil. 16(Suppl. 1), 106-111.
Huizinga, J. D., and Lammers, W. J. (2009). Gut peristalsis is governed by a multitude of cooperating mechanisms. Am. J. Physiol. Gastrointest. Liver Physiol. 296, G1-G8.

Huizinga, J. D., Liu, L. W., Fitzpatrick, A., White, E., Gill, S., Wang, X. Y., Zarate, N., Krebs, L., Choi, C., Starret, T., Dixit, D., and Ye,J.(2008a). Deficiency of intramuscular ICC increases fundic muscle excitability but does not impedenitrergic innervation. Am. J. Physiol. Gastrointest. Liver Physiol. 294, G589-G594.

Huizinga, J. D., Reed, D. E., Berezin, I., Wang, X. Y., Valdez, D. T., Liu, L. W., and Diamant, N. E. (2008b). Survival dependency of intramuscular ICC on vagal afferent nerves in the cat esophagus. Am. J. Physiol. Regul. Integr. Comp. Physiol. 294, R302-R310.

Huizinga, J. D., Stern, H. S., Chow, E., Diamant, N. E., and El-Sharkawy, T. Y. (1985). Electrophysiologic control of motility in the human colon. Gastroenterology 88, 500-511.

Huizinga, J. D., Thuneberg, L., Kluppel, M., Malysz, J., Mikkelsen, H. B., and Bernstein, A. (1995). W/kit gene required for interstitial cells of Cajal and for intestinal pacemaker activity. Nature 373, 347-349.

Huizinga, J.D., Zarate, N., and Farrugia, G. (2009). Physiology, injury, and recovery of interstitial cells of Cajal: basic and clinical science. Gastroenterology 137, 1548-1556.

Iino, S., and Nojyo, Y. (2006). Muscarinic $\mathrm{M}(2)$ acetylcholine receptor distribution in the guinea-pig gastrointestinal tract. Neuroscience 138, 549-559.

Iino, S., Ward, S. M., and Sanders, K. M. (2004). Interstitial cells of Cajal are functionally innervated by excitatory motor neurones in the murine intestine. J. Physiol. (Lond.) 556, 521-530.

Jimenez, M., Cayabyab, F. S., Vergara, P., and Daniel,E.E. (1996). Heterogeneity in electrical activity of the canine ileal circular muscle: interaction of two pacemakers. Neurogastroenterol. Motil. 8, 339-349.

Karaus, M., and Sarna, S. K. (1987). Giant migrating contractions during defecation in the dog colon. Gastroenterology 92, 925-933.

Keating, D. J., and Spencer, N. J. (2010a). Reply to "Controversies involving the role of 5-hydroxitryptamine in generating colinic migrating motor complexes: what is spontaneous?" Gastroenterology 138, 1214-1215.

Keating, D. J., and Spencer, N. J. (2010b). Release of 5-hydroxytryptamine from the mucosa is not required for the generation or propagation of colonic migrating motor complexes. Gastroenterology 138, 659-670.

Keith,A. (1915). A new theory of the causation of enterostasis. Lancet 2, 371-375.
Kito, Y., Sanders, K. M., Ward, S. M., and Suzuki, H. (2009). Interstitial cells of Cajal generate spontaneous transient depolarizations in the rat gastric fundus. Am. J. Physiol. Gastrointest. Liver Physiol. 297, G814-G824.

Koh, S. D., Sanders, K. M., and Ward, S. M. (1998). Spontaneous electrical rhythmicity in cultured interstitial cells of Cajal from the murine small intestine. J. Physiol. (Lond.) 513, 203-213.

Komuro, T. (2006). Structure and organization of interstitial cells of Cajal in the gastrointestinal tract. J. Physiol. (Lond.) 576, 653-658.

Kraichely, R. E., and Farrugia, G. (2007). Mechanosensitive ion channels in interstitial cells of Cajal and smooth muscle of the gastrointestinal tract. Neurogastroenterol. Motil. 19, 245-252.

Kunze, W. A., and Furness, J. B. (1999). The enteric nervous system and regulation of intestinal motility. Anпu. Rev. Physiol. 61, 117-142.

Lammers, W. J., and Slack, J. R. (2001). Of slow waves and spike patches. News Physiol. Sci. 16, 138-144.

Lammers, W. J., Ver Donck, L., Stephen, B., Smets, D., and Schuurkes, J. A. (2009). Origin and propagation of the slow wave in the canine stomach: the outlines of a gastric conduction system. Am. J. Physiol. Gastrointest. Liver Physiol. 296, G1200-G1210.

Leeuwe, H. (1937). On the Interstitial Cells of Cajal. Dissertation, University of Utrecht, Utrecht.

Li, M., Johnson, C. P., Adams, M. B., and Sarna, S. K. (2002). Cholinergic and nitrergic regulation of in vivo giant migrating contractions in rat colon. Am. J. Physiol. Gastrointest. Liver Physiol. 283, G544-G552.

Liu, L. W., and Huizinga, J. D. (1993). Electrical coupling of circular muscle to longitudinal muscle and interstitial cells of Cajal in canine colon. J. Physiol. (Lond.) 470, 445-461.

Lyster, D. J., Bywater, R. A., and Taylor, G. S. (1995). Neurogenic control of myoelectric complexes in the mouse isolated colon. Gastroenterology 108, 1371-1378.

McKay, C. M., and Huizinga, J. D. (2006). Muscarinic regulation of ether-a-gogo-related gene $\mathrm{K}+$ currents in interstitial cells of Cajal. J. Pharmacol. Exp. Ther. 319, 1112-1123.

Mitsui, R., and Komuro, T. (2002). Direct and indirect innervation of smooth muscle cells of rat stomach, with special reference to the interstitial cells of Cajal. Cell Tissue Res. 309, 219-227.

Nelemans, F. A., and Nauta, W. J. (1951). New concepts of the action of the peripheral autonomous nervous system. Geneeskd. Bl. 45, 47-64.

Nieuwmeyer, F., Ye, J., and Huizinga, J. D. (2006). Ava[L-Pro9,N-MeLeu10] substance $\mathrm{P}(7-11)$ (GR 73632) and $\mathrm{Sar} 9$, Met $(\mathrm{O} 2) 11$ increase distentioninduced peristalsis through activation of neurokinin-1 receptors on smooth muscle and interstitial cells of Cajal. J. Pharmacol. Exp. Ther. 317, 439-445.

Park, K. J., Hennig, G. W., Lee, H. T, Spencer, N. J., Ward, S. M., Smith, T. K., and Sanders, K. M. (2006). Spatial and temporal mapping of pacemaker activity in interstitial cells of Cajal in mouse ileum in situ. Am. J. Physiol. Cell Physiol. 290, C1411-C1427.

Park, S. J., McKay, C. M., Zhu, Y., and Huizinga, J. D. (2005). Volumeactivated chloride currents in interstitial cells of Cajal. Am. J. Physiol. Gastrointest. Liver Physiol. 289, G791-G797.

Pluja, L., Alberti, E., Fernandez, E., Mikkelsen, H. B., Thuneberg, L. and Jimenez, M. (2001). Evidence supporting presence of two pacemakers in rat colon. Am. J. Physiol. Gastrointest. Liver Physiol. 281, G255-G266.

Powell, A. K., Fida, R., and Bywater, R. A. (2003). Motility in the isolated mouse colon: migrating motor complexes, myoelectric complexes and pressure waves. Neurogastroenterol. Motil. 15, 257-266.

Powell, A. K., O'Brien, S. D., Fida, R., and Bywater, R. A. (2002). Neural integrity is essential for the propagation of colonic migrating motor complexes in the mouse. Neurogastroenterol. Motil. 14, 495-504.

Powley, T. L., Wang, X. Y., Fox, E. A., Phillips, R. J., Liu, L. W., and Huizinga, J. D. (2008). Ultrastructural evidence for communication between intramuscular vagal mechanoreceptors and interstitial cells of Cajal in the rat fundus. Neurogastroenterol. Motil. 20, 69-79.

Preiksaitis, H. G., and Diamant, N. E. (1999). Myogenic mechanism for peristalsis in the cat esophagus. Am. J. Physiol. 277, G306-G313.

Rae, M. G., Fleming, N., McGregor, D. B., Sanders, K. M., and Keef, K. D. (1998). Control of motility patterns in the human colonic circular muscle layer by pacemaker activity. J. Physiol. (Lond.) 510, 309-320.

Ramon y Cajal,S. (1893). Sur les ganglions et plexus nerveux de l' intestin. CR Soc. Biol. (Paris) 45, 217-223.

Rodriguez-Membrilla, A., Martinez, V., Jimenez, M., Gonalons, E., and Vergara, P. (1995). Is nitric oxide the final mediator regulating the migrating myoelectric complex cycle? Am. J. Physiol. 268, G207-G214.

Rumessen, J. J., Thuneberg, L., and Mikkelsen, H. B. (1982). Plexus muscularis profundus and associated interstitial cells. II. Ultrastructural 
studies of mouse small intestine. Anat. Rec. 203, 129-146.

Sanders, K. M., Koh, S. D., and Ward, S. M. (2006). Interstitial cells of Cajal as pacemakers in the gastrointestinal tract. Annu. Rev. Physiol. 68, 307-343.

Sanders, K. M., and Smith, T. K. (1986). Enteric neural regulation of slow waves in circular muscle of the canine proximal colon. J. Physiol. (Lond.) 377, 297-313.

Sarna, S., Stoddard, C., Belbeck, L., and McWade, D. (1981a). Intrinsic nervous control of migrating myoelectric complexes. Am. J. Physiol. 241, G16-G23.

Sarna, S. K., Waterfall, W. E., Bardakjian, B. L., and Lind, J. F. (1981b). Types of human colonic electrical activities recorded postoperatively. Gastroenterology 81, 61-70.

Sha, L., Farrugia, G., Harmsen, W. S., and Szurszewski, J. H. (2007). Membrane potential gradient is carbon monoxide-dependent in mouse and human small intestine. Am. J. Physiol. Gastrointest. Liver Physiol. 293, G438-G445.

Sha, L., Farrugia, G., Linden, D. R., and Szurszewski,J.H. (2010). The transwall gradient across the mouse colonic circular muscle layer is carbon monoxide dependent. FASEB J. 24, 3840-3849.

Smith, T. K., Dickson, E. J., Heredia, D. J., Hennig, G. W., and Bayguinov, P. O. (2010). Controversies involving the role of 5-hydroxytryptamine in generating colonic migrating motor complexes: what is spontaneous? Gastroenterology 138, 1213-1214.

Smith, T. K., Oliver, G. R., Hennig, G. W., O'Shea, D. M., Vanden Berghe, P., Kang, S. H., and Spencer, N. J. (2003). A smooth muscle tone-dependent stretch-activated migrating motor pattern in isolated guinea-pig distal colon. J. Physiol. (Lond.) 551,955-969.

Smith, T. K., Reed, J. B., and Sanders, K. M. (1987). Origin and propagation of electrical slow waves in circular muscle of canine proximal colon. Am. J. Physiol. 252, C215-C224.

Snape, W. J. Jr., Matarazzo, S. A., and Cohen, S. (1980). Abnormal gastrocolonic response in patients with ulcerative colitis. Gut 21, 392-396.

So, K. Y., Kim, S. H., Sohn, H. M., Choi, S. J., Parajuli, S. P., Choi, S., Yeum, C. H., Yoon, P. J., and Jun, J. Y. (2009). Carbachol regulates pacemaker activities in cultured interstitial cells of Cajal from the mouse small intestine. Mol. Cells 27, 525-531.

Spencer, N., Walsh, M., and Smith, T. K. (1999). Does the guinea-pig ileum obey the "law of the intestine?" $J$. Physiol. 517, 889-898.

Spencer, N. J., and Bywater, R. A. (2002). Enteric nerve stimulation evokes a premature colonic migrating motor complex in mouse. Neurogastroenterol. Motil. 14, 657-665.

Spencer, N. J., Bywater, R. A., Lyster, D. J., and Taylor, G. S. (1995). Electrically evoked MMCs in the isolated mouse colon. Neurogastroenterol. Motil. 7,288.

Spencer, N. J., Bywater, R. A., and Taylor, G. S. (1998a). Evidence that myoelectric complexes in the isolated mouse colon may not be of myogenic origin. Neurosci. Lett. 250, 153-156.

Spencer, N. J., Bywater, R. A., and Taylor, G. S. (1998b). Disinhibition during myoelectric complexes in the mouse colon. J. Auton. Nerv. Syst. 71, 37-47.

Spencer, N. J., and Smith, T. K. (2001). Simultaneous intracellular recordings from longitudinal and circular muscle during the peristaltic reflex in guinea-pig distal colon. J. Physiol. (Lond.) 533, 787-799.

Stanghellini, V., Cogliandro, R. F., De, G. R., Barbara, G., Morselli-Labate, A. M., Cogliandro, L., and Corinaldesi, R. (2005). Natural history of chronic idiopathic intestinal pseudo-obstruction in adults: a single center study. Clin. Gastroenterol. Hepatol. 3, 449-458.

Streutker, C. J., Huizinga, J. D., Driman, D. K., and Riddell, R. H. (2007). Interstitial cells of Cajal in health and disease. Part I: normal ICC structure and function with associated motility disorders. Histopathology 50, 176-189.

Sullivan, M.A., Snape, W.J. Jr., Matarazzo, S. A., Petrokubi, R. J., Jeffries, G., and Cohen, S. (1977). Gastrointestinal myoelectrical activity in idiopathic intestinal pseudo-obstruction. N. Engl. J. Med. 297, 233-238.

Szurszewski, J. H. (1969). A migrating electric complex of canine small intestine. Am. J. Physiol. 217, 1757-1763.

Thomsen, L., Robinson, T. L., Lee, J. C., Farraway, L. A., Hughes, M. J., Andrews, D. W., and Huizinga, J. D. (1998). Interstitial cells of Cajal generate a rhythmic pacemaker current. Nat. Med. 4, 848-851.
Thuneberg, L. (1982). Interstitial cells of Cajal: intestinal pacemaker cells? Adv. Anat. Embryol. Cell Biol. 71, $1-130$.

Thuneberg, L. (1999). One hundred years of interstitial cells of Cajal. Microsc. Res. Tech. 47, 223-238.

Thuneberg, L., and Peters, S. (2001). Toward a concept of stretch-coupling in smooth muscle. I. Anatomy of intestinal segmentation and sleeve contractions. Anat. Rec. 262, 110-124.

Tomita, T. (1981). "Electrical activity (spikes and slow waves) in gastrointestinal smooth muscle", in Smooth Muscle: An Assessment of Current Knowledge, eds E. Bulbring, A. F. Brading, A. W. Jones, and T. Tomita (London: Edward Arnold), 127-156.

Tong, W. D., Ridolfi, T. J., Kosinski, L., Ludwig, K., and Takahashi, T. (2010). Effects of autonomic nerve stimulation on colorectal motility in rats. Neurogastroenterol. Motil. 22, 688-693.

Vannucchi, M. G., Corsani, L., Bani, D., and Faussone-Pellegrini, M. S. (2002). Myenteric neurons and interstitial cells of Cajal of mouse colon express several nitric oxide synthase isoforms. Neurosci. Lett. 326, 191-195.

Walton, P. D., and Huizinga, J. D. (1989). Stimulus-dependent pacemaker activity in the distal canine lower esophageal sphincter. Can. J. Physiol. Pharmacol. 67, 1331-1335.

Wang, X. Y., Zarate, N., Soderholm, J. D., Bourgeois, J. M., Liu, L. W., and Huizinga, J. D. (2007). Ultrastructural injury to interstitial cells of Cajal and communication with mast cells in Crohn's disease. Neurogastroenterol. Motil. 19, 349-364.

Ward, S. M. (2000). Interstitial cells of Cajal in enteric neurotransmission. Gut 47(Suppl.4),iv40-iv43; discussion iv52.

Ward, S. M., Beckett, E. A., Wang, X., Baker, F., Khoyi, M., and Sanders, K. M. (2000). Interstitial cells of Cajal mediate cholinergic neurotransmission from enteric motor neurons. $J$. Neurosci. 20, 1393-1403.

Ward, S. M., Burns, A. J., Torihashi, S., and Sanders, K.M. (1994). Mutation of the proto-oncogene c-kit blocks development of interstitial cells and electrical rhythmicity in murine intestine. $J$. Physiol. (Lond.) 480, 91-97.

Won, K. J., Sanders, K. M., and Ward, S. M. (2005). Interstitial cells of Cajal mediate mechanosensitive responses in the stomach. Proc. Natl. Acad. Sci. U.S.A. 102, 14913-14918.

Wood, J. D. (1975). Neurophysiology of Auerbach's plexus and control of intestinal motility. Physiol. Rev. 55, 307-324.

Yoneda, S., Fukui, H., and Takaki, M. (2004). Pacemaker activity from submucosal interstitial cells of Cajal drives high-frequency and low-amplitude circular muscle contractions in the mouse proximal colon. Neurogastroenterol. Motil. 16, 621-627.

Yoneda, S., Takano, H., Takaki, M., and Suzuki, H. (2002). Properties of spontaneously active cells distributed in the submucosal layer of mouse proximal colon. J. Physiol. (Lond.) 542, 887-897.

Young, H. M., Ciampoli, D., Southwell, B. R., and Newgreen, D. F. (1996). Origin of interstitial cells of Cajal in the mouse intestine. Dev. Biol. 180, 97-107.

Zhang, Y., Lomax, A. E., and Paterson, W. G. (2010). P2Y1 receptors mediate apamin-sensitive and -insensitive inhibitory junction potentials in murine colonic circular smooth muscle. J. Pharmacol. Exp. Ther. 333, 602-611.

Conflict of Interest Statement: The authors declare that the research was conducted in the absence of any commercial or financial relationships that could be construed as a potential conflict of interest.

Received: 03 January 2011; accepted: 13 July 2011; published online: 05 August 2011. Citation: Huizinga JD, Martz S, Gil V, Wang X-Y, Jimenez M and Parsons S (2011) Two independent networks of interstitial cells of Cajal work cooperatively with the enteric nervous system to create colonic motor patterns. Front. Neurosci. 5:93. doi: 10.3389/fnins.2011.00093

This article was submitted to Frontiers in Autonomic Neuroscience, a specialty of Frontiers in Neuroscience.

Copyright @ 2011 Huizinga, Martz, Gil, Wang, Jimenez and Parsons. This is an open-access article subject to a non-exclusive license between the authors and Frontiers Media SA, which permits use, distribution and reproduction in other forums, provided the original authors and source are credited and other Frontiers conditions are complied with. 